\title{
Divergent Properties in Structural Isomers of Triphenylamine-Based Covalent Organic Frameworks
}

Ly D. Tran ${ }^{1,2}$, Kayla F. Presley ${ }^{1,2}$, Jason K. Streit ${ }^{1,2}$, Jennifer Carpena-Núñez ${ }^{1,2}$, Lucas K. Beagle ${ }^{1,2}$, Tod A. Grusenmeyer ${ }^{1}$, Matthew J. Dalton ${ }^{1}$, Richard A. Vaia ${ }^{1}$, Lawrence F. Drummy ${ }^{1}$, Nicholas R. Glavin ${ }^{1}$, Luke A. Baldwin ${ }^{1}$

${ }^{1}$ Materials and Manufacturing Directorate, Air Force Research Laboratory, Wright-Patterson AFB, OH 45433, USA

${ }^{2}$ UES, Inc., Beavercreek, OH 45431, USA

\section{Table of Contents}

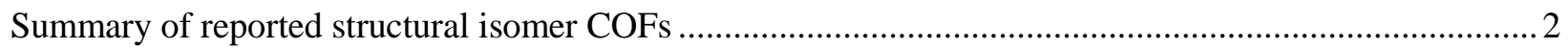

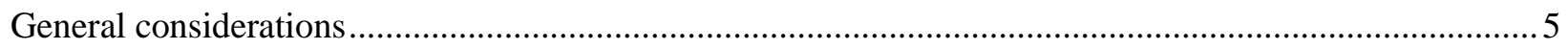

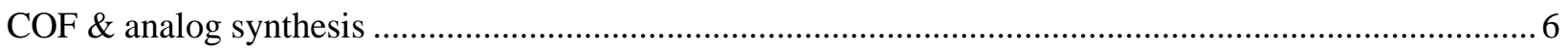

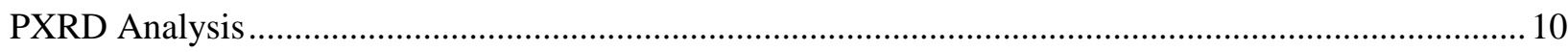

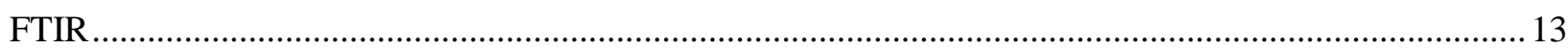

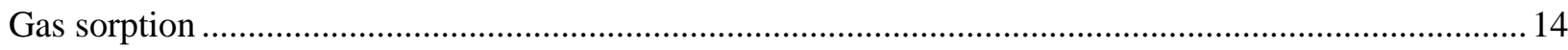

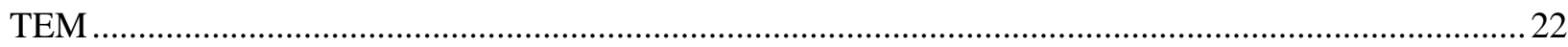

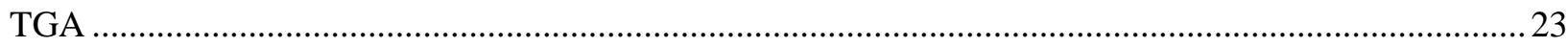

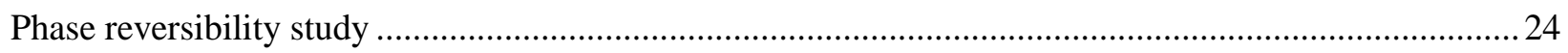

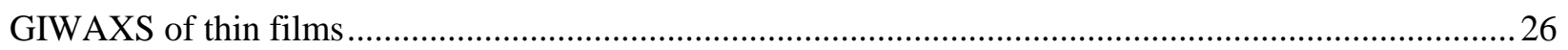

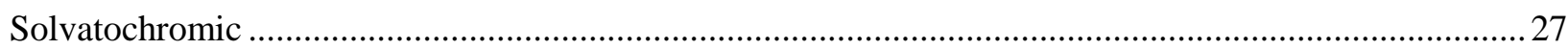

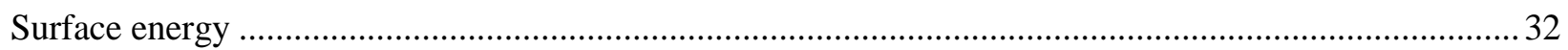

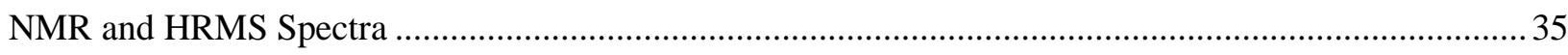

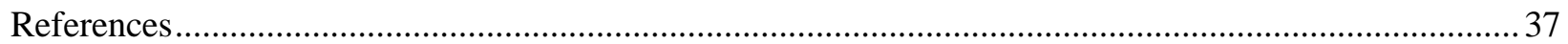


Summary of reported structural isomer COFs

Table S1: Summary of structural isomer COFs reported in separated publications

\begin{tabular}{|c|c|c|c|c|}
\hline $\begin{array}{l}\text { Entr } \\
\mathrm{y}\end{array}$ & Linker 1 & Linker 2 & $\begin{array}{l}\text { Name/Properti } \\
\text { es/Synthesis }\end{array}$ & Ref \\
\hline 1 & $\mathrm{O}_{5}$ & No & $\begin{array}{l}\text { TFPB-TAPT } \\
\text { Band gap } 2.74 \\
\text { eV } \\
\text { UV-Vis max } \\
470 \mathrm{~nm} \\
\text { BET } 455 \mathrm{~m}^{2} / \mathrm{g}\end{array}$ & 1,2 \\
\hline 2 & $\mathrm{NH}_{2}$ & & $\begin{array}{l}\text { TBI-COF } \\
\text { Band gap } 2.49 \\
\text { eV } \\
\text { BET } 907 \mathrm{~m}^{2} / \mathrm{g}\end{array}$ & 3,4 \\
\hline 3 & $\mathrm{O}_{3}$ & & $\begin{array}{l}\text { Synthesis: } 120 \\
{ }^{\circ} \mathrm{C}, 3 \text { days }\end{array}$ & 5 \\
\hline 4 & & & $\begin{array}{l}\text { TAPB-PDA } \\
\text { COF } \\
\text { Synthesis } 70 \\
{ }^{\circ} \mathrm{C}, 4 \mathrm{~h}\end{array}$ & 6 \\
\hline
\end{tabular}




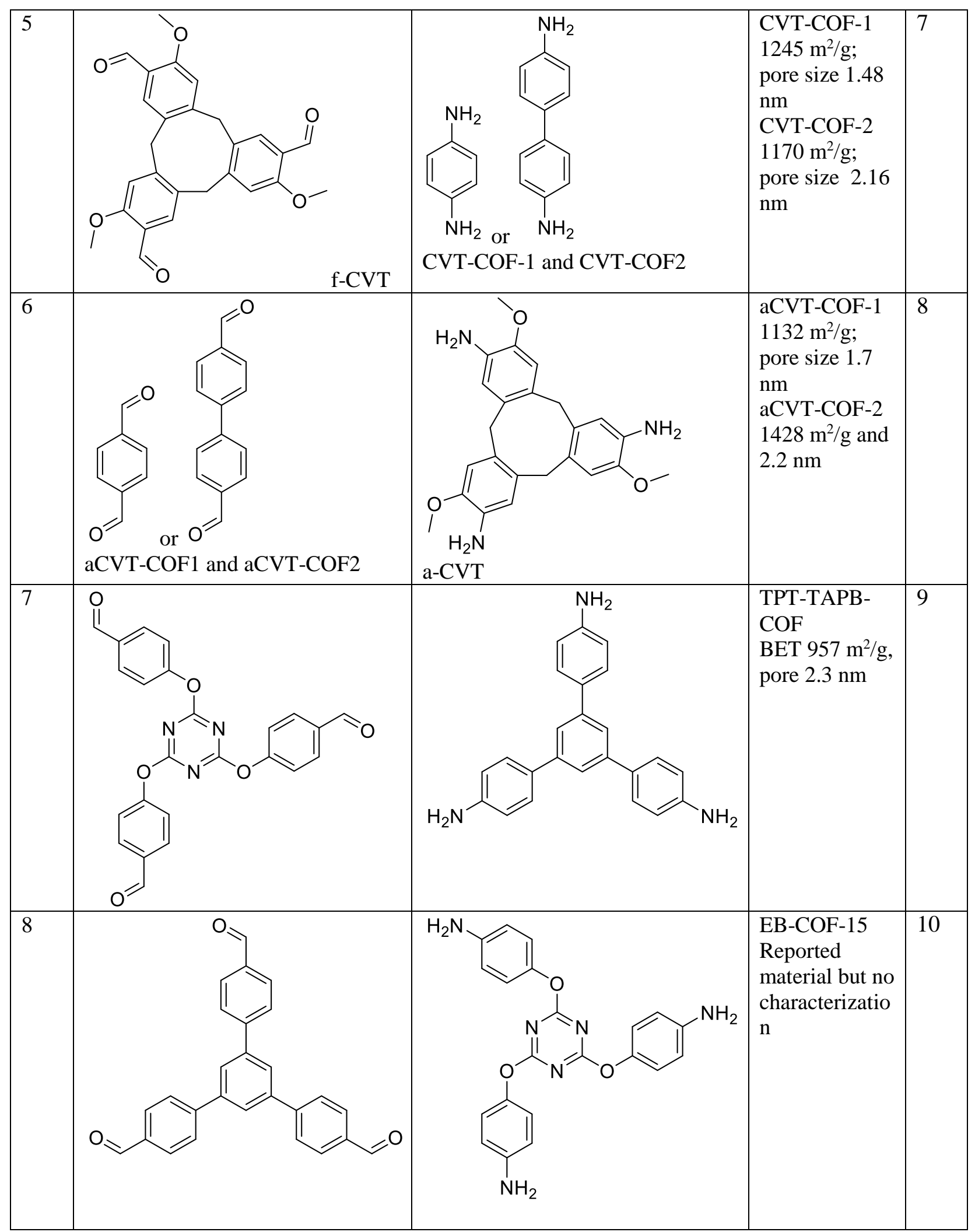




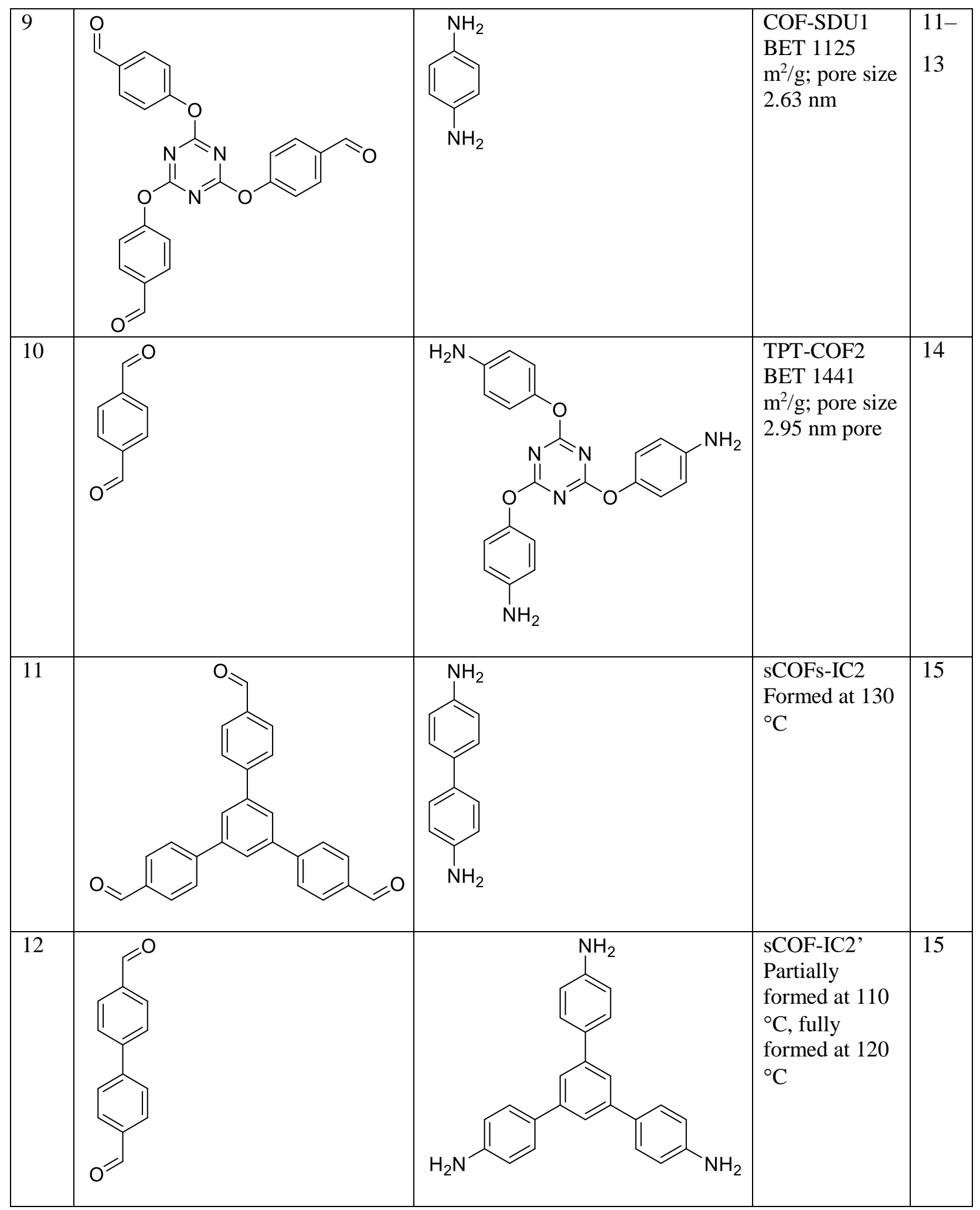


General considerations: All reagents were obtained from commercial vendors and used asreceived unless otherwise noted. Elemental analyses were performed by Galbraith Laboratories.

FTIR IR Spectroscopy was performed using a Bruker alpha-P FT-IR in ATR mode using solid powders of materials.

NMR ${ }^{1} \mathrm{H}-\mathrm{NMR}$ and ${ }^{13} \mathrm{C}$ NMR spectra were obtained on Bruker 400 spectrometer using TMS as a standard.

HRMS was obtained at the Ohio State University. All experiments were performed on a Thermo-Fisher LTQ-Orbitrap mass spectrometer equipped with an ESI source operated in positive ion mode. Samples were prepared in methanol and infused into the source at a rate of $5 \mu 1 / \mathrm{min}$. Optimal conditions were: spray voltage $5 \mathrm{KV}$, capillary temperature $275^{\circ} \mathrm{C}$, capillary voltage of $25 \mathrm{~V}$ and a tube lens voltage of 40 $\mathrm{V}$. The resolution on the Orbitrap was set to 30,000 and the scan range was m/z $100-1200$. One minute of data was acquired in profile mode and averaged.

PXRD: Powder X-ray diffraction data were collected on a Rigaku Smartlab diffractometer. The Cu$\mathrm{K} \alpha(1.5406 \AA) \mathrm{X}$-ray radiation source was operated at $40 \mathrm{~V}$ and $44 \mathrm{~mA}$. Samples were evenly dispersed on a standard silicon wafer from Rigaku. Samples were then transferred to the diffractometer and analyzed under ambient conditions.

GIWAXS: Grazing-incidence GIWAXS measurements were performed with a Xeuss 3.0 (XENOCS, France) system. The system is equipped with a Genix 3D (The $\mathrm{Cu}-\mathrm{K} \alpha$ ) X-ray radiation source and a Pilatus3R 300K detector (Dectris, Switzerland). The sample-to-detector distance was set at $51 \mathrm{~mm}$ and the grazing incident angle was set at $0.15^{\circ}$ in the case of IISERP-COF2 film and $51 \mathrm{~mm}, 0.20^{\circ}$ in the case of TAPA-PDA COF film. Experiments were performed under vacuum atmosphere. Data was processed by SAXSGUI v2.23.33 software.

UV-Vis: UV-Vis spectra were collected in the UV-Vis-NIR CRAIG Microspectrophotometer. COF was deposited onto a glass slide as a thin film through solvothermal reaction. UV-VIS spectra of the COF thin films were obtained through transmission mode.

UV-Vis spectra of solutions for COF analogs: Absorption spectra were collected in the UV-Vis-NIR Carry 5000 (Agilent) spectrophotometer.

Gas sorption measurements: $\mathrm{N}_{2}$ sorption experiments were carried out using an ASAP 2020 and ASAP 2020 plus (Micromeritics, Norcross, Georgia, USA). He (99.999\%, used to determine void volume), Argon (99.999\% purity) were purchased from Weiler Welding Co. Inc., $\mathrm{N}_{2}$ (99.999\% purity) was purchased from Indiana Oxygen Company and used as received. An activated sample (70-120 mg) was charged into a sample cell subsequently transferred to the degas unit for degassing and sorption apparatus for measurement at $77 \mathrm{~K}\left(\mathrm{~N}_{2}\right.$ isotherm) or $87 \mathrm{~K}$ (Ar isotherm).

TGA: A Q500 TGA (TA instrument, New Castle, Delaware, USA) was used to obtain thermogravimetric data. Samples $(2-3 \mathrm{mg})$ were heated and analyzed in a platinum pan under a flow of dry nitrogen.

Fluorescence: Room temperature emission spectra were obtained using an Edinburgh Instruments FLS1000 luminescence spectrometer equipped with a $450 \mathrm{~W}$ xenon arc lamp. This excitation source was attached to a double grating Czerny-Turner monochromator with 1800 grooves $/ \mathrm{mm}$, a linear dispersion of $1.7 \mathrm{~nm} / \mathrm{mm}$, and a focal length of $2 \times 325 \mathrm{~mm}$. The luminescence emission was collected perpendicular to the excitation source with an extended red photomultiplier tube (PMT) detector in cooled housing operated at $-22^{\circ} \mathrm{C}$. Prior to reaching the detector, the luminescence output passed through an emission 
monochromator with 1800 grooves $/ \mathrm{mm}$, a linear dispersion of $1.7 \mathrm{~nm} / \mathrm{mm}$, and a focal length of $325 \mathrm{~mm}$. Each sample was positioned across the diagonal of a quartz cuvette using a custom cuvette insert so that the sample was oriented in a front-scattering geometry at $45^{\circ}$ relative to both the excitation source and the detector. The emission spectra for IISERP-COF2 was collected over 410-900 nm using an excitation wavelength of $380 \mathrm{~nm}$, a $3 \mathrm{~nm}$ excitation bandwidth, and a $1 \mathrm{~nm}$ emission bandwidth. A $400 \mathrm{~nm}$ longpass filter (Thorlabs) was placed in front of the emission monochromator. The TAPA-PDA COF film was excited at $450 \mathrm{~nm}$, and the emission spectra was collected between 505-900 nm using a 495 long-pass filter (Thorlabs) in front of the emission monochromator. The emission and excitation bandwidths were set to 5 and $3 \mathrm{~nm}$, respectively. All spectra were collected using a step size of $1 \mathrm{~nm}$, a dwell time of $0.2 \mathrm{~s}$, and 5 repeated scans.

FL Characterization of solutions for COF analog studies: Room temperature emission spectra of TAPAbenzaldehyde and TFPA-aniline in THF and methanol were collected using the Edinburgh Instruments FLS1000 luminescence spectrometer. The emission spectra for both molecules were collected using an excitation wavelength of $350 \mathrm{~nm}$. For TAPA-benzaldehyde, the excitation and emission bandwidths were both set to $6 \mathrm{~nm}$. For TFPA-aniline, the excitation and emission bandwidths were to set to 6 and $3 \mathrm{~nm}$, respectively All emission spectra were obtained using a step size of $1 \mathrm{~nm}$, a dwell time of $0.2 \mathrm{~s}$, and 5 repeated scans.

\section{TEM}

Sample preparation for TEM experiments: From the suspension of TAPA-PDA COF in acetone, the solution was sonicated 15-30 minutes. The suspension was drop casted onto the 30s-plasma treated grid and the sample was allowed to dry in the hood for 1-2 hours.

TEM images of the activated TAPA-PDA COF ( $\beta$-phase), prepared following the method described above, were captured with FEI Talos (Thermo Fisher Scientific) and Ceta camera at an accelerating voltage of $200 \mathrm{kV}$. TAPA-PDA COF is a beam sensitive material, and low dose imaging techniques were used to avoid beam damage of the material, with imaging conditions optimized off the region of interest then moved to the region of interest.

TEM image processing: a digital Fourier Transform from the raw high resolution micrograph was calculated using the FFT function in Gatan's Digital Micrograph suite.16. Once the image was transformed to an FFT, the d-spacing was extracted by measuring the distance between the two symmetric diffraction points in the FFT image $\left(\mathrm{x}, \mathrm{nm}^{-1}\right)$. The repeat distance (d-spacing) was calculated from $\mathrm{x}$ using the equation.

$d-\operatorname{spacing}(n m)=\frac{2}{x}$

Contact angle measurement: Contact angle of water droplet on COF thin film was measure by OneAttension Optical Tensiometer through senssile drop contact angle experiment set up.

\section{COF \& analog synthesis}

Synthesis of TAPA-PDA COF

To a $40 \mathrm{ml}$ amber vial equipped with a stirrer was added tris(4-aminophenyl)amine (145 mg, $0.5 \mathrm{mmol}$ ), terephtharaldehyde (100 mg, $0.75 \mathrm{mmol}), 1,4$-dioxane $(4 \mathrm{ml})$, and mesitylene $(1 \mathrm{ml})$. The resulting mixture was purged with $\mathrm{N}_{2}$, sonicated for 15 mins then heated at $70{ }^{\circ} \mathrm{C}$ for 10 mins with stirring. After that, acetic acid $10.5 \mathrm{M}(2.5 \mathrm{ml})$ was added while stirring. The reaction mixture was purged with $\mathrm{N}_{2}$, 
capped and heated at $70{ }^{\circ} \mathrm{C}$ without stirring for 22 hours. After completion, reaction mixture was allowed to cool down to RT. The dark red solid product was washed extensively with methanol, then acetone and is kept in acetone until the next step.

\section{Synthesis of TAPA-PDA COF films}

Glass slides were washed with detergent, rinsed with DI water, ethanol, and acetone and let dry before the reaction.

To a $40 \mathrm{ml}$ amber vial equipped with a stirrer was added tris(4-aminophenyl)amine (145 mg, $0.5 \mathrm{mmol}$ ), terephtharaldehyde $(100 \mathrm{mg}, 0.75 \mathrm{mmol}), 1,4$-dioxane $(4 \mathrm{ml})$, and mesitylene $(1 \mathrm{ml})$. The resulting mixture was purged with $\mathrm{N}_{2}$, sonicated for 15 mins then heated at $70{ }^{\circ} \mathrm{C}$ for 10 mins with stirring. After that, acetic acid $10.5 \mathrm{M}(2.5 \mathrm{ml})$ was added while stirring. Stirring was stopped and glass slides were inserted. The reaction mixture was purged with $\mathrm{N}_{2}$, capped and heated at $70{ }^{\circ} \mathrm{C}$ without stirring for 22 hours. After completion, reaction mixture was allowed to cool down to RT. Thin film of TAPA-PDA COF on glass slide was removed from reaction mixture and was washed extensively with methanol, then acetone and is kept in acetone until the next step.

Vacuum activation of TAPA-PDA COF: From the suspension of COF in acetone or methanol, the solvent was decanted. The remaining damp material was placed under vacuum until all solvents evaporated. PXRD analysis was used to monitor the crystallinity of the COF during the process. Results showed only the presence of amorphous material after 30 minutes under vacuum.

\section{Flow $\mathrm{N}_{2}$ activation of TAPA-PDA $\mathrm{COF}^{6}$}

TAPA-PDA COF was stored in acetone. From acetone, solvent was exchanged to DCM (3 times, 1 hour each) then n-hexane ( 3 times, 1 hour each) and stored in n-hexane overnight. The TAPA-PDA COF in nhexane was then transferred to a $25 \mathrm{ml}$ round bottom flask. Hexane was then decant and the flask was capped with a septum. A flask was then placed under the constant flow of $\mathrm{N}_{2}$ and was heated to $150{ }^{\circ} \mathrm{C}$ during 1.5 hours and kept at $150^{\circ} \mathrm{C}$ for 3 hours, followed with cooling down to RT for 30 mins. This process yielded an activated TAPA-PDA COF as an orange color solid $(203.1 \mathrm{mg})$ with $93 \%$ yield.

\section{Activation of TAPA-PDA COF using perfluoropentane $^{16}$}

TAPA-PDA COF was stored in acetone. From acetone, solvent was exchanged to DCM (3 times, 1 hour each) then n-hexane ( 2 times, 1 hour each), then perfluoropentane (3 times, 1 hour each) and stored in perfluoropentane overnight. The TAPA-PDA COF in perfluoropentane was then transferred to a $15 \mathrm{ml}$ Schlenk tube. Most of perfloropentane was then decant and the wet material was activated by high vacuum for 4 hours. Activated material was characterized by gas sorption, which gave BET surface area of $605 \mathrm{~m}^{2} / \mathrm{g}$.

Elemental analysis: TAPA-PDA COF $\left(\mathrm{C}_{60} \mathrm{H}_{42} \mathrm{~N}_{8}\right)$ calculated value $\mathrm{C}, 82.36 ; \mathrm{H}, 4.84 ; \mathrm{N}, 12.81$ Found $\mathrm{C}$, 80.07; H, 4.73; N, 12.30.

\section{Synthesis of IISERP-COF2}

Table S2. Screening conditions for IISERP-COF2

\begin{tabular}{|l|l|l|l|l|l|}
\hline & Solvent & Temperature & Time & Note & Product \\
\hline 1 & $\begin{array}{l}\text { 1,4-Dioxane/Mesitylene/Acetic } \\
\text { acid } 10.5 \mathrm{M}\end{array}$ & $70{ }^{\circ} \mathrm{C}$ & 20 hours & $\begin{array}{l}\text { Condition for } \\
\text { synthesizing } \\
\text { TAPA-PDA }\end{array}$ & Amorphous \\
\hline
\end{tabular}




\begin{tabular}{|c|c|c|c|c|c|}
\hline & & & & $\begin{array}{l}\text { COF in this } \\
\text { work }\end{array}$ & \\
\hline 2 & $\begin{array}{l}\text { 1,4-Dioxane/Mesitylene/Acetic } \\
\text { acid } 10.5 \mathrm{M}\end{array}$ & $70^{\circ} \mathrm{C}$ & 3 days & & Amorphous \\
\hline 3 & $o$-DCB/EtOH/ Acetic acid 3M & $100{ }^{\circ} \mathrm{C}$ & 3 days & & Amorphous \\
\hline 4 & $o-\mathrm{DCB} / \mathrm{EtOH} /$ Acetic acid 3M & $120^{\circ} \mathrm{C}$ & 3 days & $\begin{array}{l}\text { Degas by } \\
\text { bubbling with } \\
\mathrm{N}_{2}\end{array}$ & $\begin{array}{l}\text { Low } \\
\text { crystallinity }\end{array}$ \\
\hline 5 & $o$-DCB/EtOH/ Acetic acid 3M & $120^{\circ} \mathrm{C}$ & 3 days & $\begin{array}{l}\text { Using freeze- } \\
\text { pump-thaw } \\
\text { cycles before } \\
\text { heating }\end{array}$ & $\begin{array}{l}\text { High } \\
\text { crystallinity }\end{array}$ \\
\hline
\end{tabular}

IISERP-COF2 was synthesized followed the reported procedure with a small modification (this method is called method 1). ${ }^{17,18}$ To a $15 \mathrm{ml}$ Schlenk flask equipped with a stirrer was added tris(4-formylphenyl) amine (30 mg, $0.09 \mathrm{mmol})$, 1,4-diaminobenzene (15 mg, $0.14 \mathrm{mmol})$ and ethanol $(1.125 \mathrm{ml})$. The resulting mixture was stirred at $\mathrm{RT}$ for 15 mins. $o$-Dichlorobenzene $(1.125 \mathrm{ml})$ was then added and stirring was continued for 15 mins. Acetic acid (3M, $0.094 \mathrm{ml})$ was added. The resulting mixture was rapidly frozen to $77 \mathrm{~K}$ by liquid nitrogen, degassed through 3 cycle of freeze-pump-thaw, sealed under vacuum and heated at $120^{\circ} \mathrm{C}$ for 3 days. After completion, reaction mixture was cooled down to RT and a yellow solid product was obtained. Product was washed with copious amount of methanol, acetone and was stored in acetone until the next step.

IISERP-COF2 was activated using flow of nitrogen method, the same method to activate TAPA-PDA COF. This process yielded activated IISERP-COF2 as a yellow color solid (35.4 mg) with $88 \%$ yield.

\section{Synthesis of IISERP-COF2 films}

To a $15 \mathrm{ml}$ Schlenk flask equipped with a stirrer was added tris(4-formylphenyl) amine (30 mg, 0.09 $\mathrm{mmol}), 1,4$-diaminobenzene $(15 \mathrm{mg}, 0.14 \mathrm{mmol})$ and ethanol $(1.125 \mathrm{ml})$. The resulting mixture was stirred at RT for 15 mins. $o$-Dichlorobenzene $(1.125 \mathrm{ml})$ was then added and stirring was continued for 15 mins. Acetic acid (3M, $0.094 \mathrm{ml})$ was added and glass slides were inserted. The resulting mixture was rapidly frozen to $77 \mathrm{~K}$ by liquid nitrogen, degassed through 3 cycle of freeze-pump-thaw, sealed under vacuum and heated at $120{ }^{\circ} \mathrm{C}$ for 3 days. After completion, reaction mixture was cooled down to RT and a yellow solid product was obtained. Thin films of IISERP-COF2 on glass slides were removed and washed with copious amount of methanol, acetone and was stored in acetone until the next step.

Small molecules synthesis (COF analogs)

Scheme 1 Synthesis of A) TAPA-PDA COF analog, B) IISERP-COF2 analog 

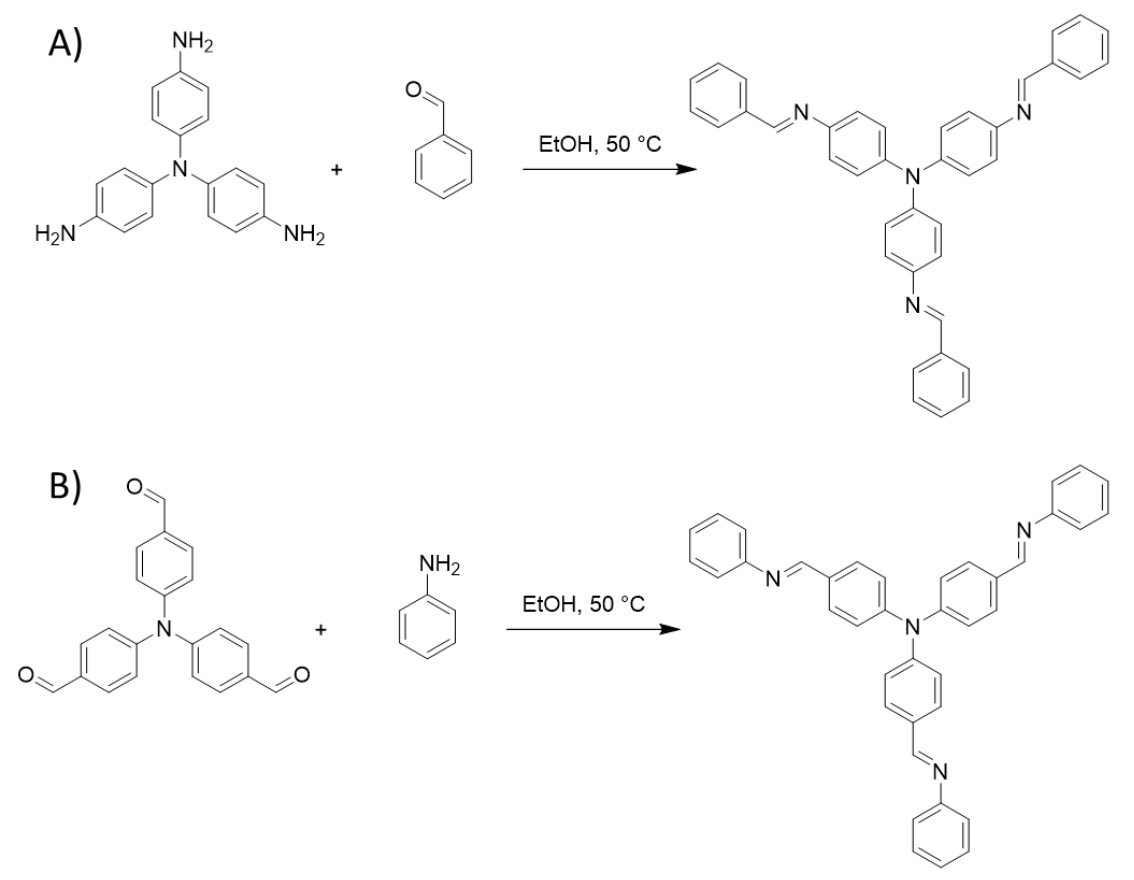

TAPA-PDA COF analog: To a 20ml vial equipped with a stirrer was added tris(4-aminophenyl)amine (TAPA) (580 mg, $2 \mathrm{mmol}, 1$ equiv), benzaldehyde (639.9 mg, $6.03 \mathrm{mmol}, 3.0$ equiv), and ethanol (10 $\mathrm{ml})$. Resulting mixture was sonicated for 5 mins then heated at $50{ }^{\circ} \mathrm{C}$ for 5 hours with stirring. After completion, reaction mixture was cooled down to $\mathrm{RT}, 5 \mathrm{ml} \mathrm{DI} \mathrm{H}_{2} \mathrm{O}$ was added and the yellow precipitate was collected by filtration and washed with ethanol. After drying under vacuum, $974.4 \mathrm{mg}$ of crude product was obtained. The crude reaction mixture was further purified by column chromatography in Heptane/EtOAc/1\% $\mathrm{Et}_{3} \mathrm{~N}$ eluent system (10:1 to 4:1). After column chromatography, $208.5 \mathrm{mg}$ of crude reaction mixture gave $60.4 \mathrm{mg}$ of product $\left(25 \%\right.$ calculated yield). FT-IR $\left(\mathrm{cm}^{-1}\right) 1619,1574,1495,1449$, $1312,1268,1190,1166,1105,1071,965,878,831,754,720,689,653 .{ }^{1} \mathrm{H} \mathrm{NMR}\left(400 \mathrm{MHz}, \mathrm{CDCl}_{3}\right) \delta$ (ppm) $8.53(\mathrm{~s}, 3 \mathrm{H}), 8.0-7.80(\mathrm{~m}, 6 \mathrm{H}), 7.60-7.35(\mathrm{~m}, 9 \mathrm{H}), 7.24-7.10(\mathrm{~m}, 12 \mathrm{H}) .{ }^{13} \mathrm{C}$ NMR $(100 \mathrm{MHz}$, $\left.\left.\mathrm{CDCl}_{3}\right) \delta(\mathrm{ppm}) 158.80,146.66,145.98,136.41,131.17,128.78,128.68,124.67,122.13 . \mathrm{HRMS}_{(\mathrm{ESI}}{ }^{+}\right)$ Calculated $\mathrm{C}_{39} \mathrm{H}_{30} \mathrm{~N}_{4}[\mathrm{M}+\mathrm{H}]^{+}$555.2543, Measured $\mathrm{M}^{+} \mathrm{H} 555.2529$

4-[(Phenylimino)methyl]-N,N-bis[4-[(phenylimino)methyl]phenyl]benzenamine (IISERP-COF2 analog): To a $20 \mathrm{ml}$ vial equipped with a stirrer was added tris(4-formylphenyl)amine (TFPA) (132 mg, $0.4 \mathrm{mmol}$, 1 equiv), ethanol $(5 \mathrm{ml})$ was added and the vial was sonicated for 5 mins and stirred to dissolve TFPA (note: TFPA won't dissolve completely in ethanol). Aniline (123 mg, $1.32 \mathrm{mmol}, 3.3$ equiv.) was dissolved in ethanol $(2 \mathrm{ml})$ and the resulting mixture was added into the TFPA solution. Ethanol ( $3 \mathrm{ml})$ was used to rinse aniline vial. The resulting mixture was heated to $50{ }^{\circ} \mathrm{C}$ overnight. After completion, reaction mixture was cooled down to RT. Crude product was collected by filtration and washed by ethanol. After drying under vacuum, $177 \mathrm{mg}$ of crude product was obtained. Ethanol (1 ml) was added to crude product $(50 \mathrm{mg})$ and the solution was stirred overnight. Filtration followed by washing with ethanol and dry under vacuum gave $30.8 \mathrm{mg}$ of a final product as a yellow solid (49\% calculated yield). This compound is known. ${ }^{19,20}{ }^{1} \mathrm{H}$ NMR $\left(400 \mathrm{MHz}, \mathrm{CDCl}_{3}\right) \delta(\mathrm{ppm}) 8.43(\mathrm{~s}, 3 \mathrm{H}), 7.91-7.79(\mathrm{~m}, 6 \mathrm{H}), 7.46-7.34$ $(\mathrm{m}, 6 \mathrm{H}), 7.29-7.13(\mathrm{~m}, 15 \mathrm{H})$. 


\section{PXRD Analysis}

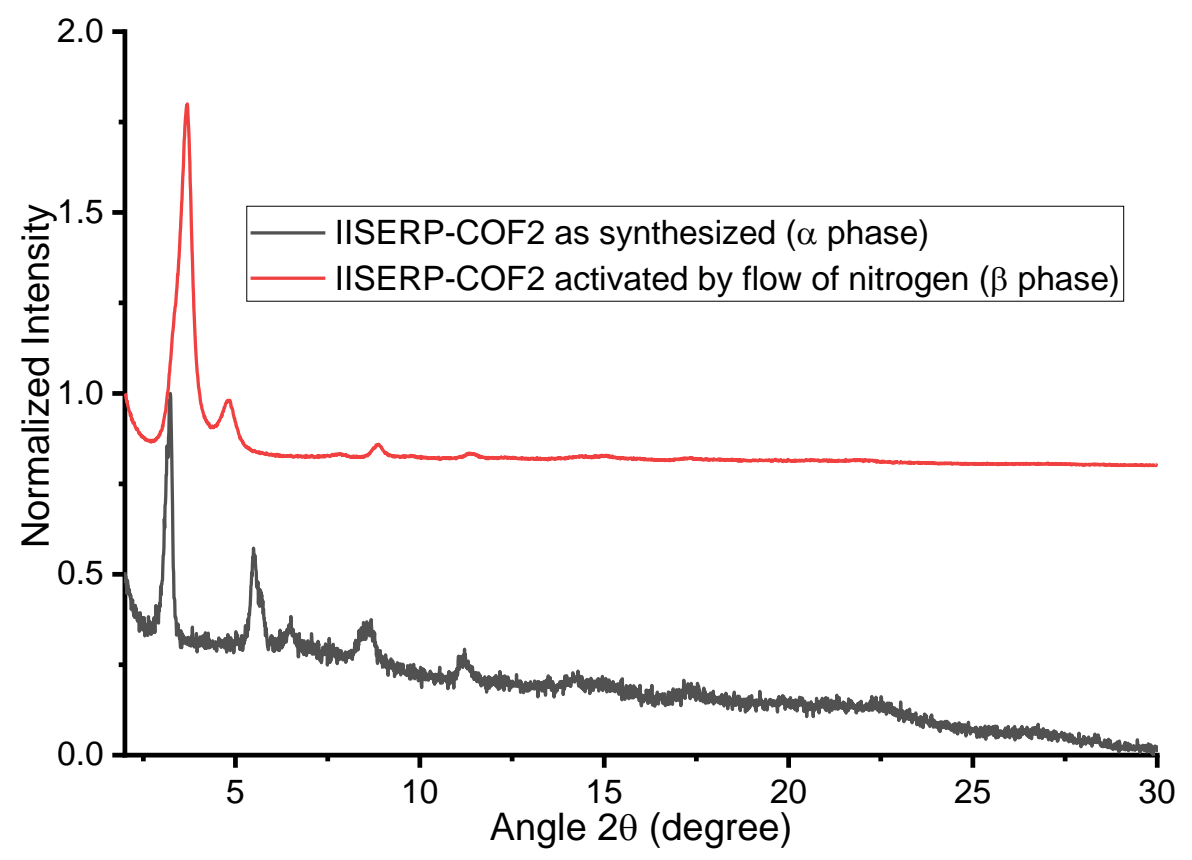

Figure S1. PXRD of IISERP-COF2 as synthesized ( $\alpha$ ) phase (black line, PXRD was taken from the COF suspensions in acetone) and activated $(\beta)$ phase (red line)

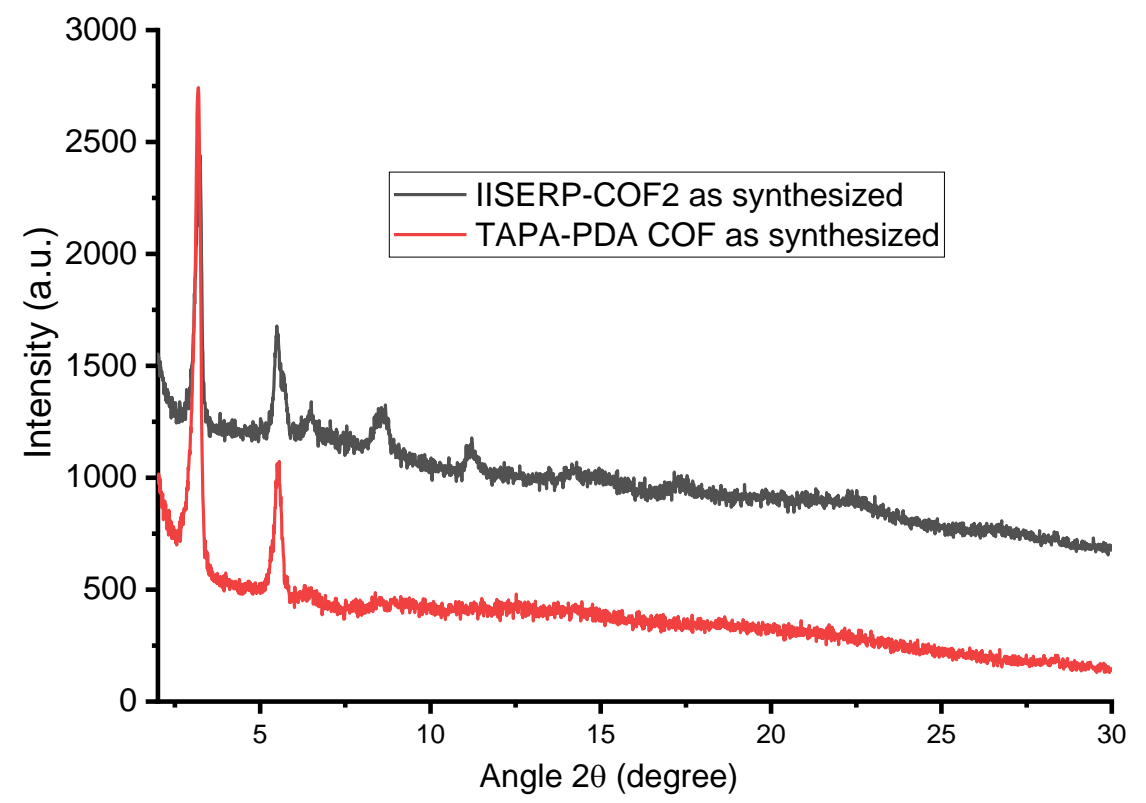

Figure S2. PXRD of as synthesized $(\alpha)$ phase of TAPA-PDA COF (red line) and IISERP-COF2 (black line). In both cases, PXRD was taken from the COF suspensions in acetone. The patterns match, indicating that they have the same stacking conformation of 2D COF sheets 


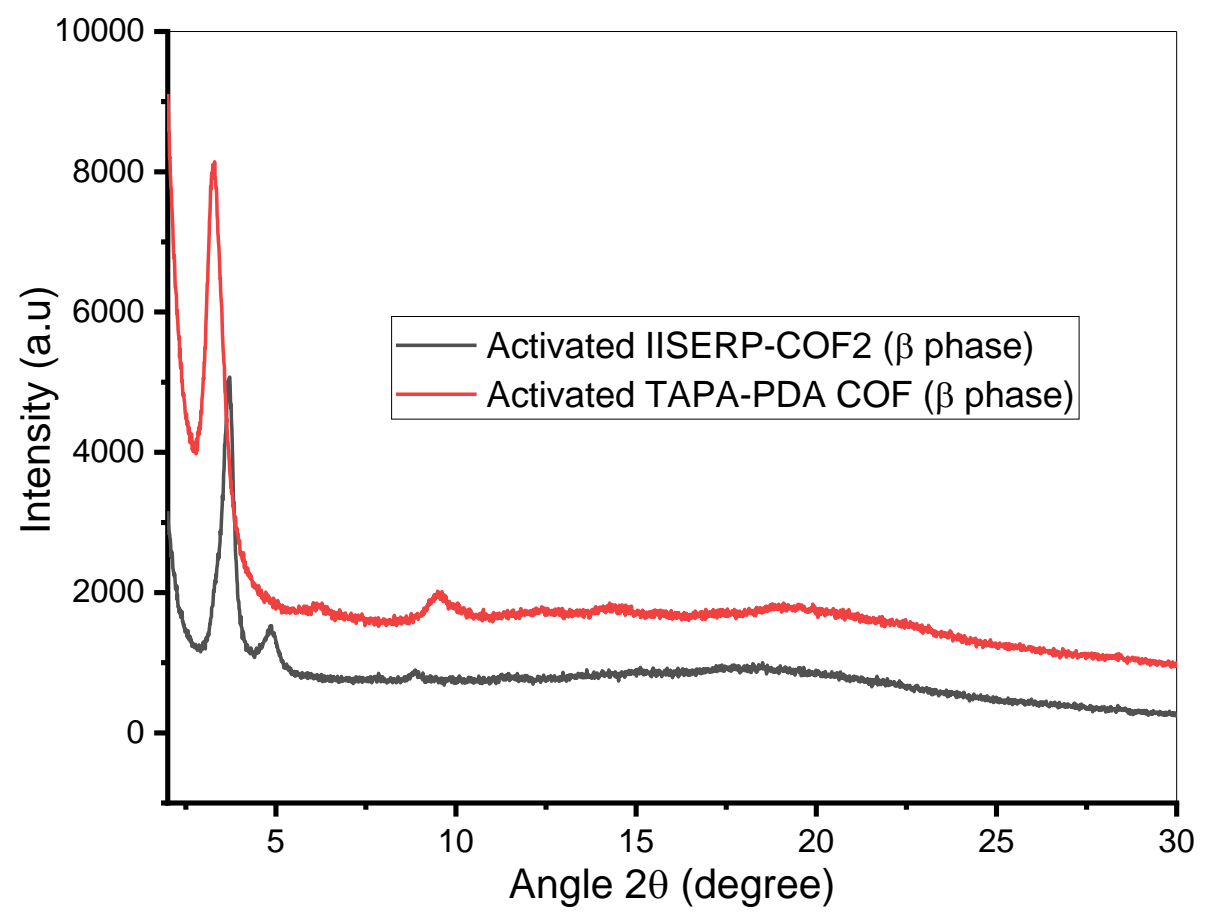

Figure S3. PXRD of activated ( $\beta$ ) phase of TAPA-PDA COF (red) and IISERP-COF2 (black).

Comparing of PXRD of TAPA-PDA COF's (red) and IISERP-COF2's (black) activated ( $\beta$ ) phase indicated that they have different type of structure thus, TAPA-PDA COF activated phase is not at stagger stacking of 2D layers. 
$\underline{\text { Structure simulation for calculating simulated PXRD of TAPA-PDA COF } \beta \text { phase }}$

Activated TAPA-PDA COF structure modelling were performed using Materials Studio 7.0 by Accelrys (Biovia). A model of TAPA-PDA COF as synthesized material ( $\alpha$ phase, eclipsed conformation) was built based on the reported IISERP-COF2 alpha phase since their PXRDs match (Figure S2). The unit cell of TAPA-PDA COF $\alpha$ phase: $a=b=31.71 \AA, c=4.2 \AA, \alpha=\beta=90^{\circ}, \gamma=120^{\circ}$.

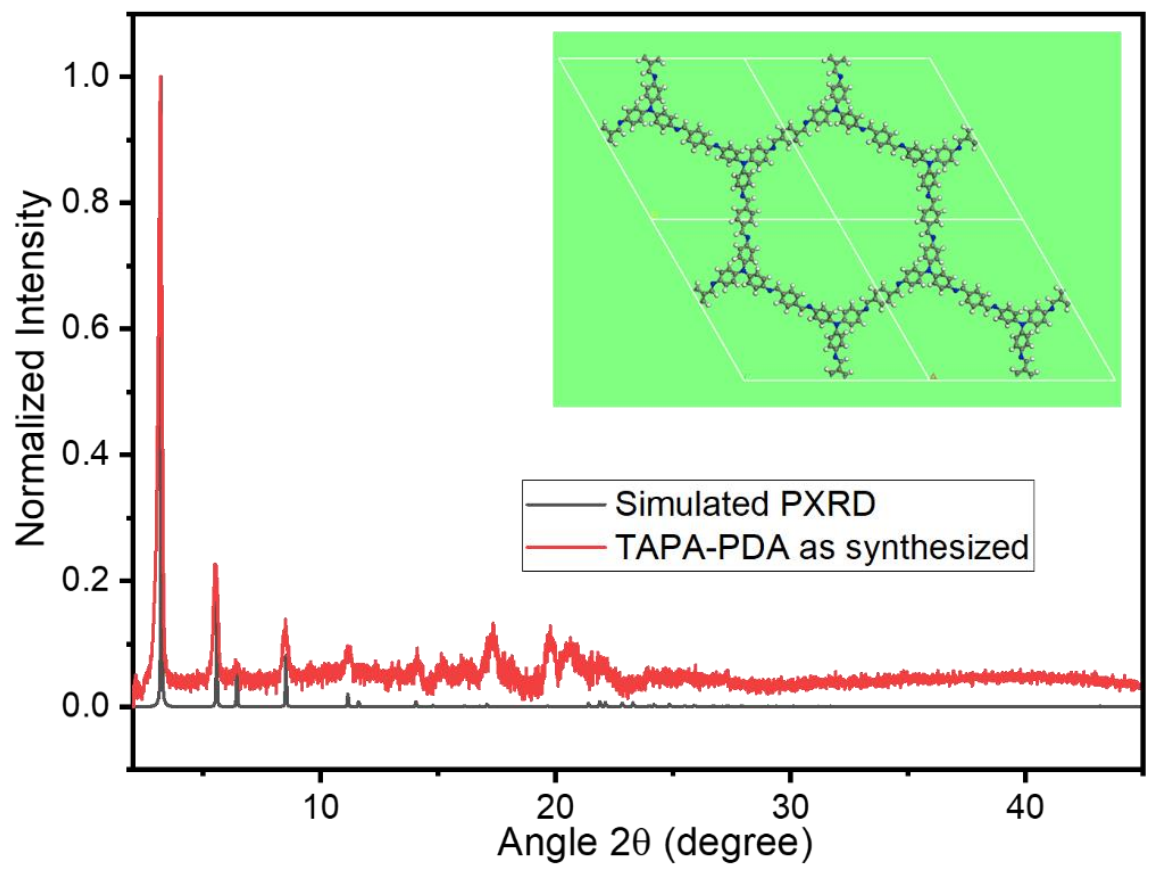

Figure S4. Comparison of PXRD patterns of TAPA-PDA COF as synthesized ( $\alpha$ phase, red line) and simulated PXRD of TAPA-PDA COF model shown in the top-right corner. The two patterns match. To prevent solvent evaporation from the as synthesized material during Xray analysis, which can cause the phase transition from $\alpha$ to $\beta$ phase of TAPA-PDA COF, TAPA-PDA COF as synthesized sample was coated with mineral oil. After base-line subtraction, the PXRD was obtained as shown in Figure S4.

From the base model of TAPA-PDA COF $\alpha$ phase, slipped stacking models with 3 shifting layers were built with shifting along $a$, or $b$ or ab directions with shifting distance of $0.1,0.2,0.3,0.4$ in ratio to the unit cell dimension. Simulated PXRD of these models were then generated and compared with the experimental activated TAPA-PDA COF ( $\beta$ phase). The results indicated that, PXRDs of the models with the same shifting distance are similar, regardless of the shifting direction (a, or b or ab) and the smaller ratio (0.1) gave a PXRD pattern that match better with the experimental data. As a consequence, ab was chosen as the shifting direction and 0.91 .7 and $1.8 \AA$ were chosen as shifting distances for the next set of layers based on previously reported slipped stacking COF. ${ }^{21,22}$ In each model of the new set, 9 layers of 2D COF were built. The results showed that PXRD of models with 1.7 and $1.8 \AA$ of shifting distance are similar. The model that gave simulated PXRD which matches best with PXRD of activated TAPA-PDA COF, is the one with shifting distance of $1.7 \AA$ (Figure S5). These simulated data, together with TEM, porosity analysis, support our hypothesis that TAPA-PDA COF is a slip stacking conformation. However, due to the broadness of PXRD peaks, it is difficult to identify a precise stacking distance or direction based on PXRD simulation. Further studies using DFT calculation would be needed to give a clearer and deeper understanding about the slip stacking of TAPA-PDA COF. 


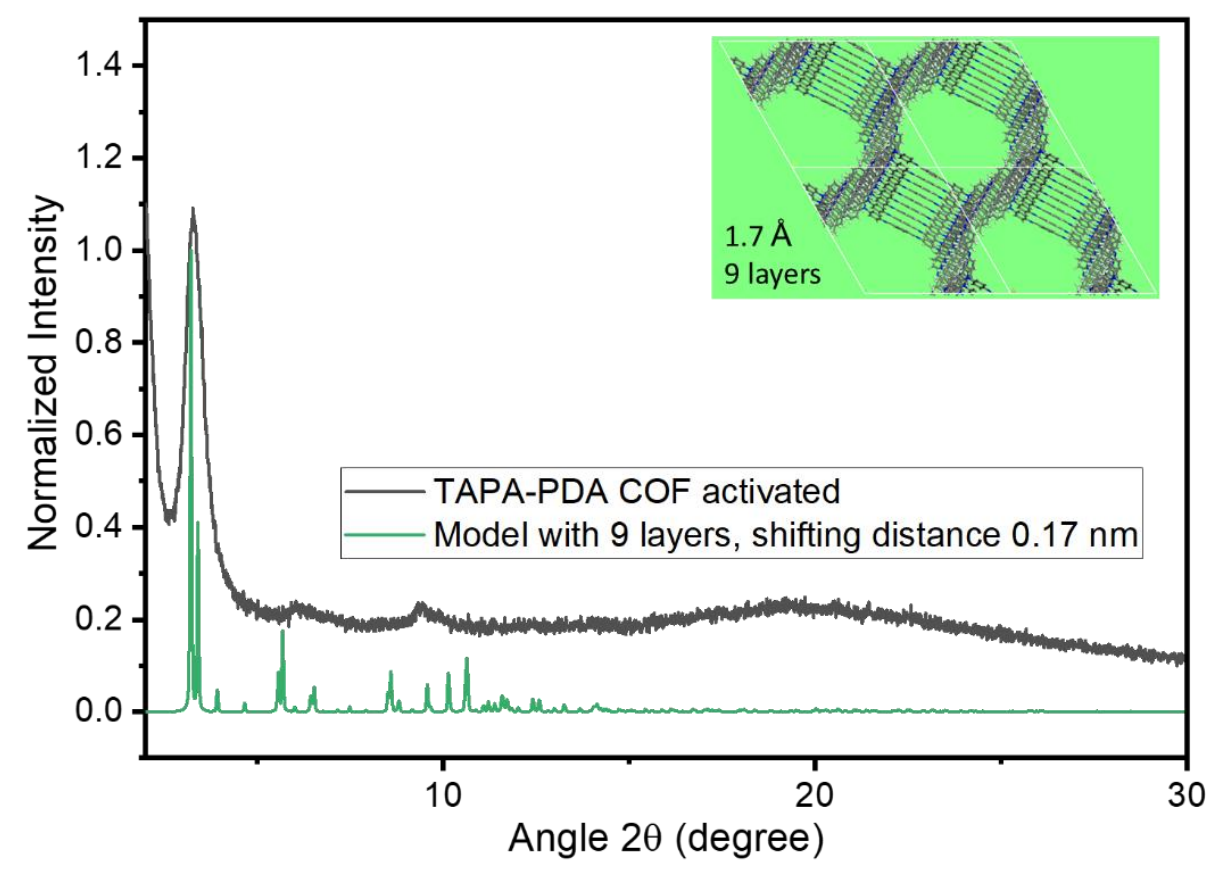

Figure S5. Comparison of PXRD patterns of activated TAPA-PDA COF ( $\beta$ phase, black line) and simulated PXRD of TAPA-PDA COF model shown in the top-right corner. The model includes 9 layers with the shifting distance of $1.7 \AA$.

\section{FTIR}

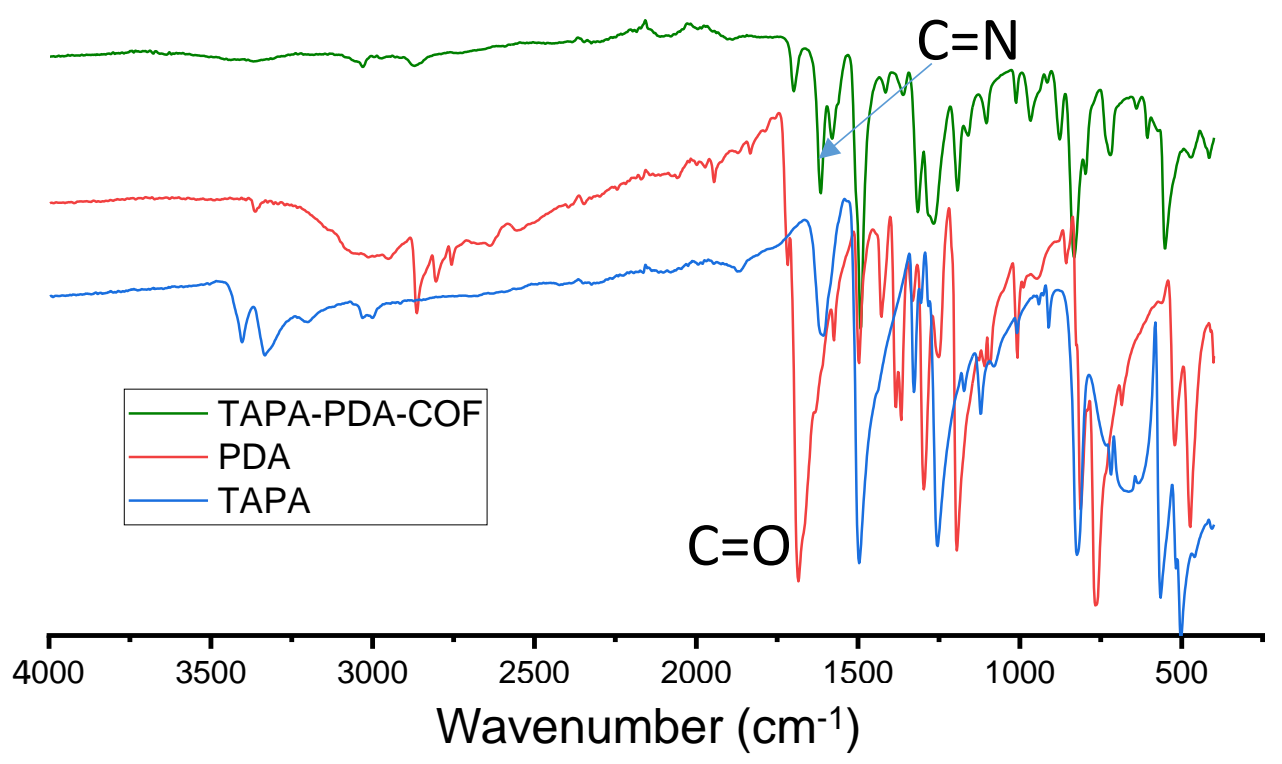

Figure S6. FTIR of TAPA-PDA COF (green), monomers PDA (red), and TAPA (blue) 


\section{Gas sorption}

\section{BET SA calculation of TAPA-PDA COF}

a)

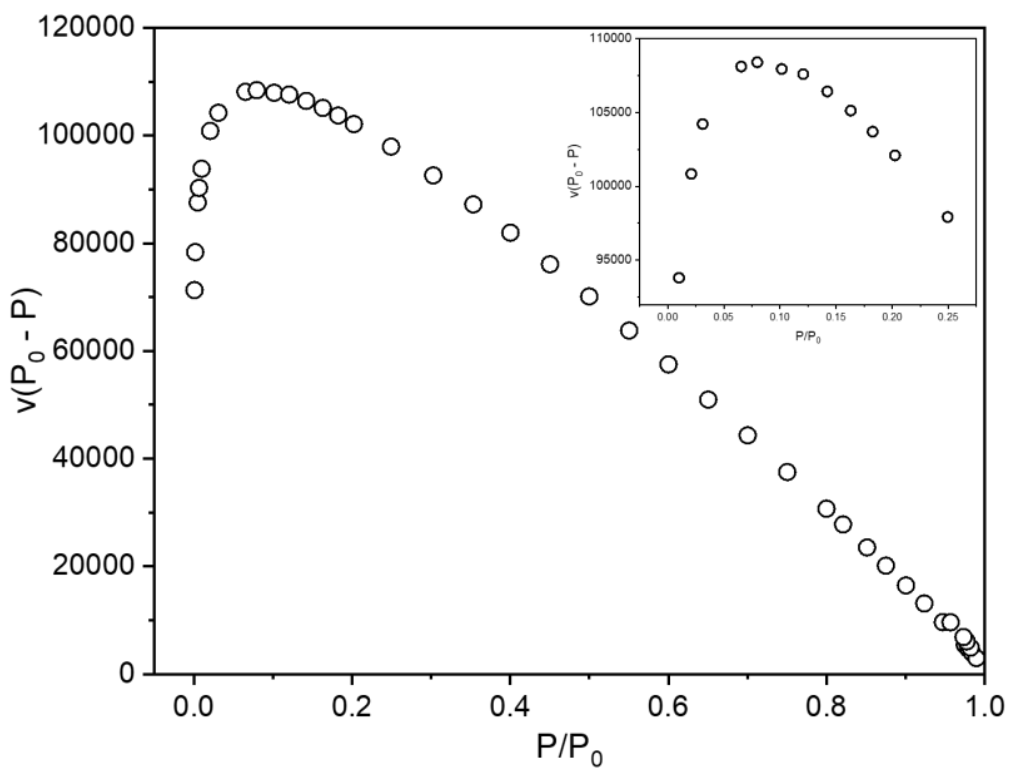

b)

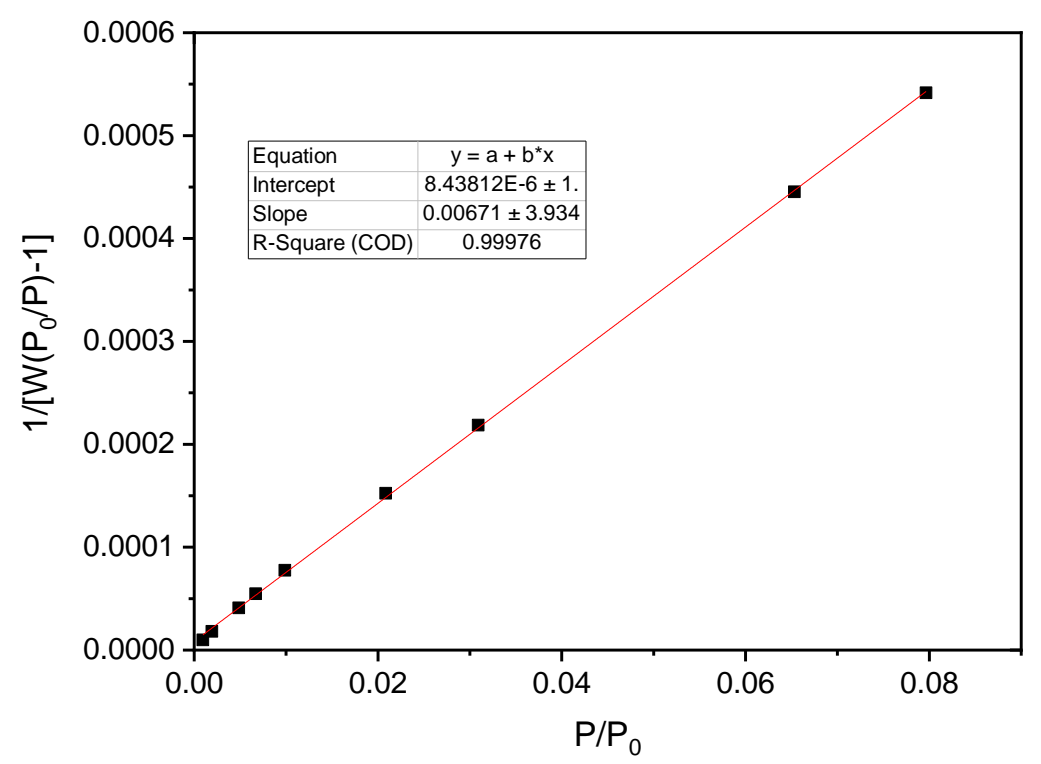

Figure S7. Evaluation of BET surface area of TAPA-PDA COF from $\mathrm{N}_{2}$ isotherm. a) Consistency criterion plot for determining $\mathrm{P} / \mathrm{P}_{0}$ range for BET analysis, ${ }^{23,24}$ insert: pressure region between $\mathrm{P} / \mathrm{P}_{0}=0.01$ and 0.25 b) BET plot using points below $\mathrm{P} / \mathrm{P}_{0}=0.08$. The BET surface area was determined to be 648 $\mathrm{m}^{2} / \mathrm{g}$. 
Pore size distribution (PSD)

PSD of TAPA-PDA COF through Ar sorption

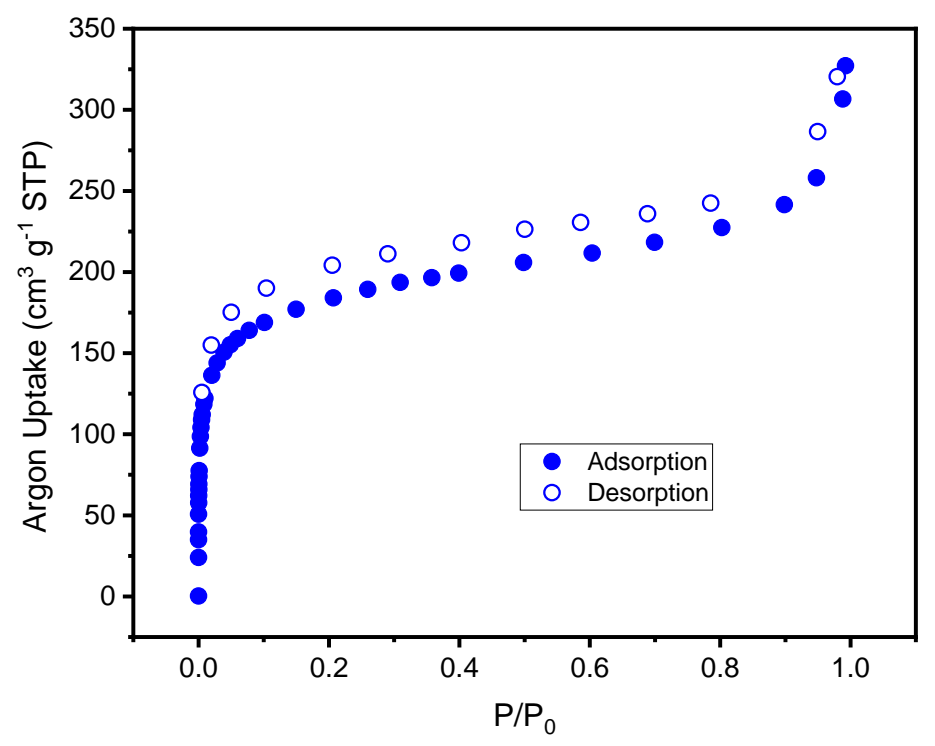

Figure S8. Ar sorption of TAPA-PDA COF

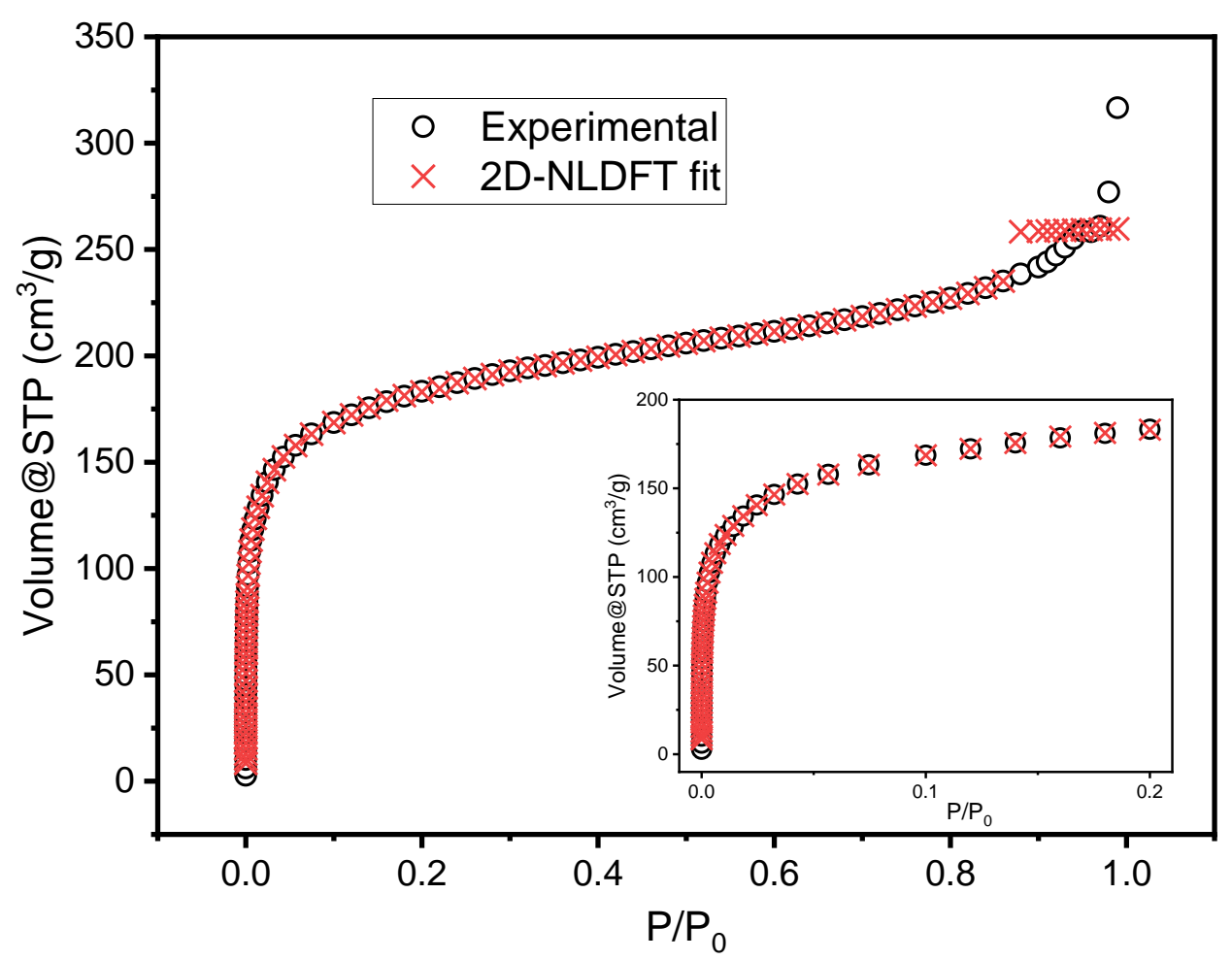

Figure S9. 2D-NLDFT model of Argon isotherm for TAPA-PDA COF based on cylindrical pores in a MOF-1 surface. Insert shows the fitting at low pressure region between 0 and $0.2 \mathrm{P} / \mathrm{P}_{0}$. 


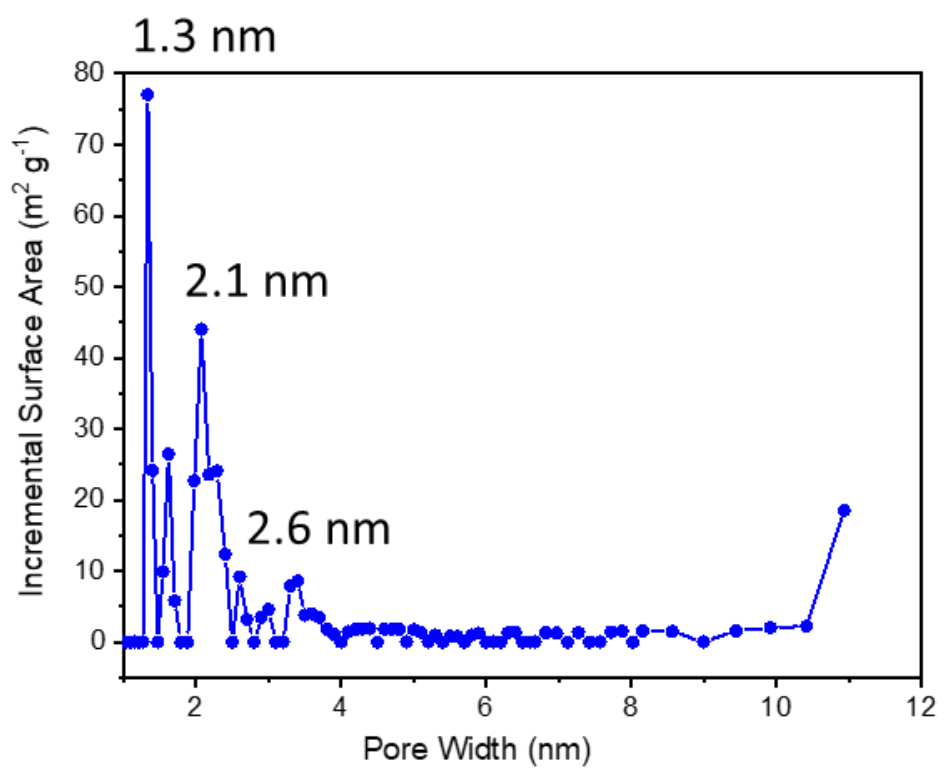

Figure S10. Full PSD of TAPA-PDA COF

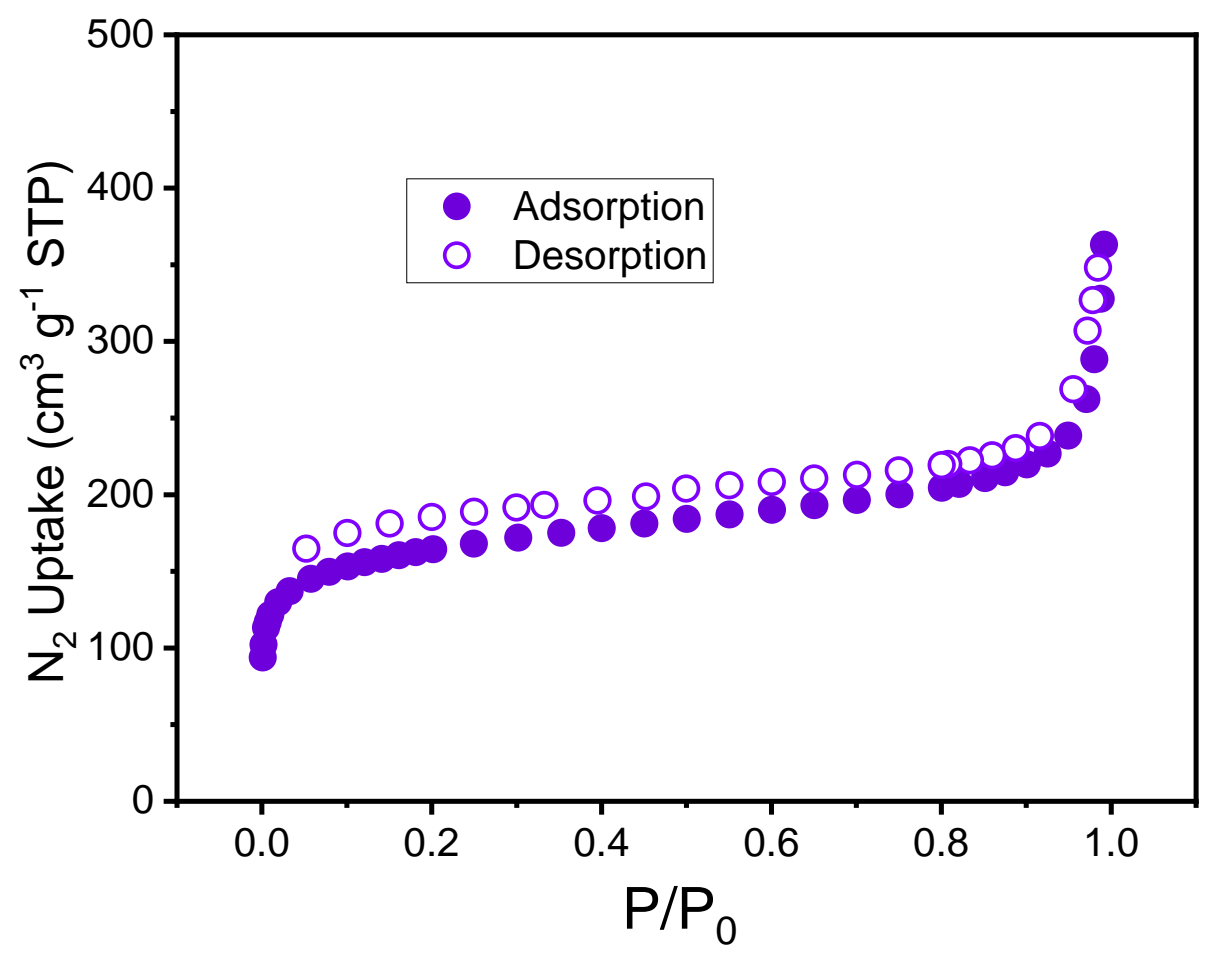

Figure S11. Nitrogen isotherm of TAPA-PDA COF activated by perfluoropentane method. Calculation of BET SA based on the isotherm gave the value of $605 \mathrm{~m}^{2} / \mathrm{g}$. 
Porosity and surface area characterization of IISERP-COF2

Table S3. List of IISERP-COF2 samples prepared and activated by different methods and their BET SA

\begin{tabular}{|l|l|l|l|}
\hline Sample & Method of synthesis & Method of activation & BET \\
\hline $\begin{array}{l}\text { IISERP-COF2 } \\
\text { sample 1 }\end{array}$ & $\begin{array}{l}\text { Method 1 } \\
\text { (freeze-pump-thaw) } \\
\text { See page 8 }\end{array}$ & $\begin{array}{l}\text { Flow of N } 2 \text { activation } \\
\text { See page 8 }\end{array}$ & $1359 \mathrm{~m}^{2} / \mathrm{g}$ \\
\hline $\begin{array}{l}\text { IISERP-COF2 } \\
\text { sample 2 }\end{array}$ & $\begin{array}{l}\text { Method 1 } \\
\text { (freeze-pump-thaw) } \\
\text { See page 8 }\end{array}$ & $\begin{array}{l}\text { Activation by heat } \\
\text { See additional studies of } \\
\text { IISERP COF2 synthesis and } \\
\text { activation }\end{array}$ & $851 \mathrm{~m}^{2} / \mathrm{g}$ \\
\hline $\begin{array}{l}\text { IISERP-COF2 } \\
\text { sample 3 }\end{array}$ & $\begin{array}{l}\text { Method 2 } \\
\text { (only freeze) } \\
\text { See additional studies of IISERP } \\
\text { COF2 synthesis and activation }\end{array}$ & $\begin{array}{l}\text { Activation by heat } \\
\text { See additional studies of } \\
\text { IISERP COF2 synthesis and } \\
\text { activation }\end{array}$ & $343 \mathrm{~m}^{2} / \mathrm{g}$ \\
\hline
\end{tabular}

$\underline{\mathrm{N}}_{2}$ sorption and Surface area measurement of IISERP-COF2 sample 1

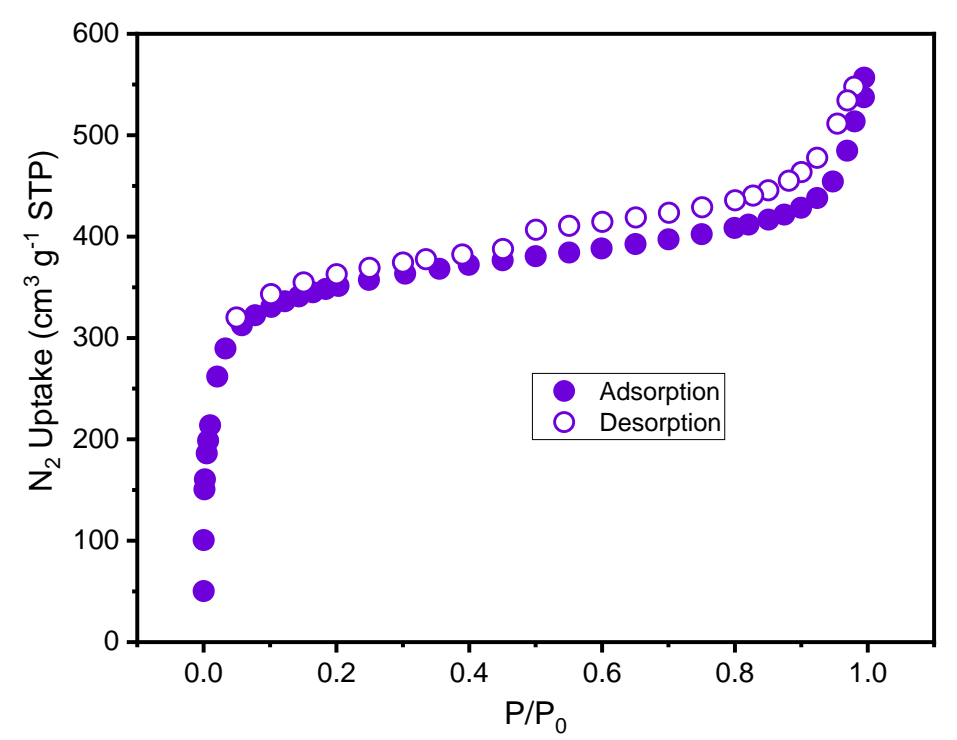

Figure $\mathrm{S} 12 . \mathrm{N}_{2}$ sorption of IISERP-COF2 sample 1 synthesized by method 1 with freeze-pump-thaw and activated with flow of nitrogen activation method 
A)

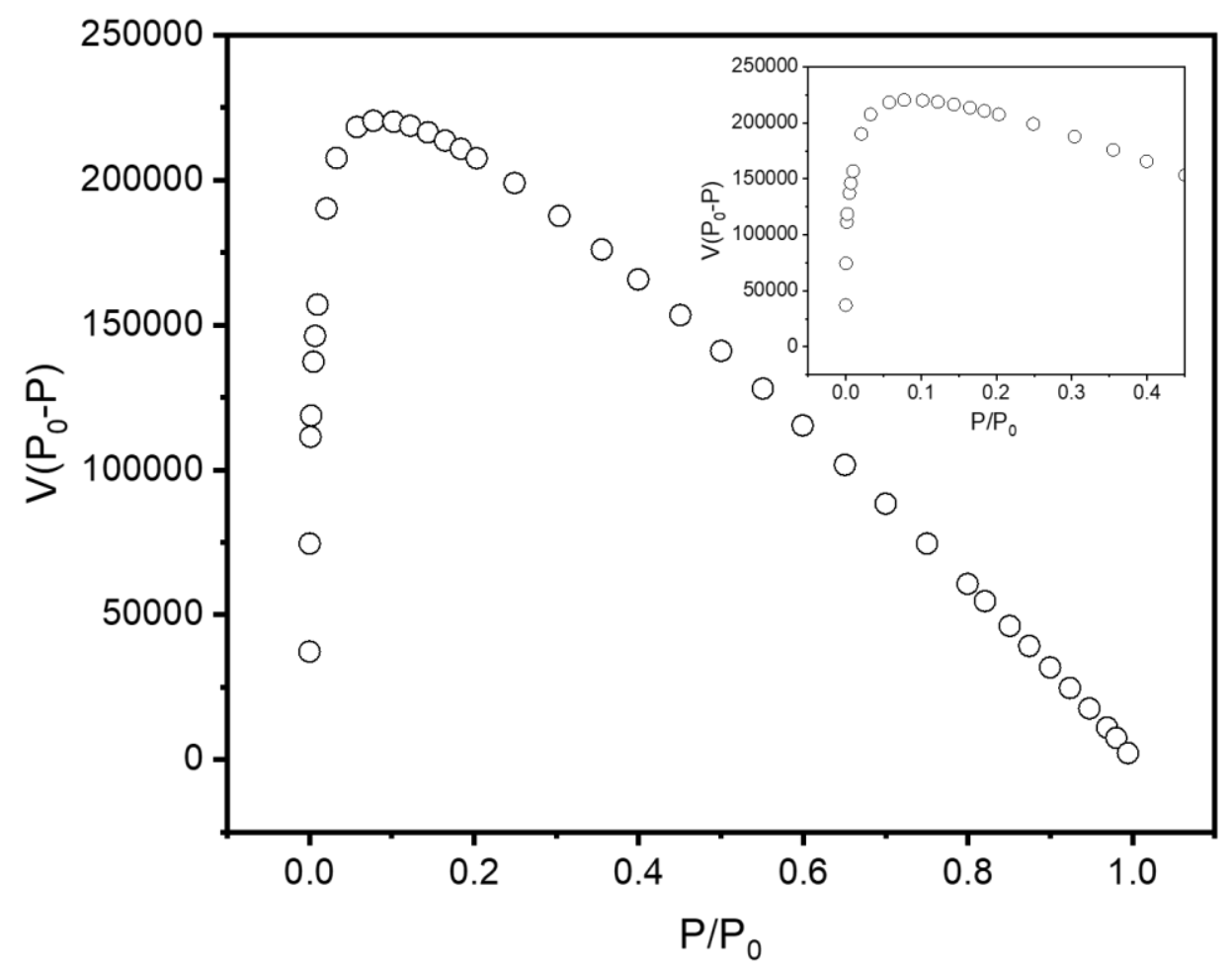

B)

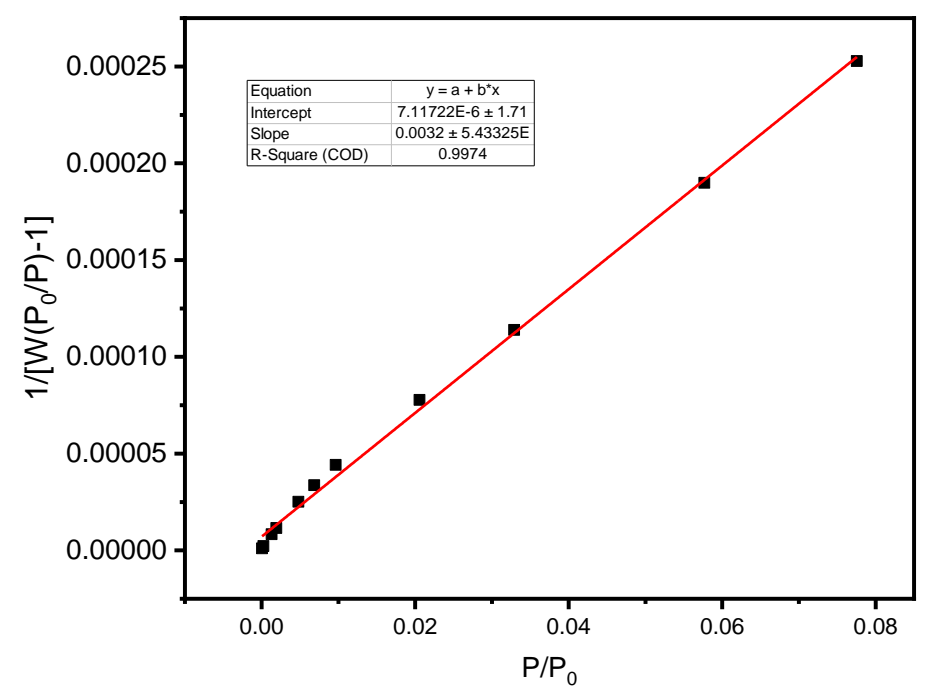

Figure S13. Evaluation of BET surface area of IISERP-COF2 sample 1 from $\mathrm{N}_{2}$ isotherm. a) Consistency criterion plot for determining $\mathrm{P} / \mathrm{P}_{0}$ range for BET analysis, ${ }^{23,24}$ insert: pressure region between $\mathrm{P} / \mathrm{P}_{0}=0.01$ and 0.45 . b) BET plot using points below $\mathrm{P} / \mathrm{P}_{0}=0.08$. The BET surface area was determined to be 1359 $\mathrm{m}^{2} / \mathrm{g}$. 


\section{PSD IISERP-COF2 sample 1}

Ar sorption of IISERP-COF2 sample 1

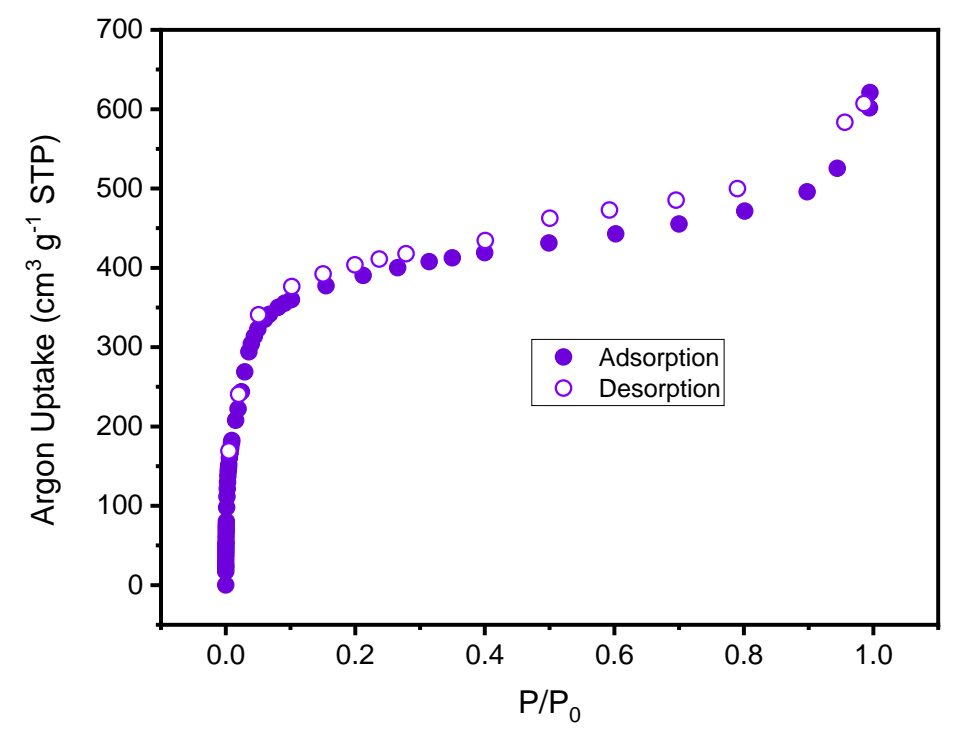

Figure S14. Ar sorption of IISERP-COF2 sample 1 synthesized by method 1 with freeze-pump-thaw and activated with flow of nitrogen activation method

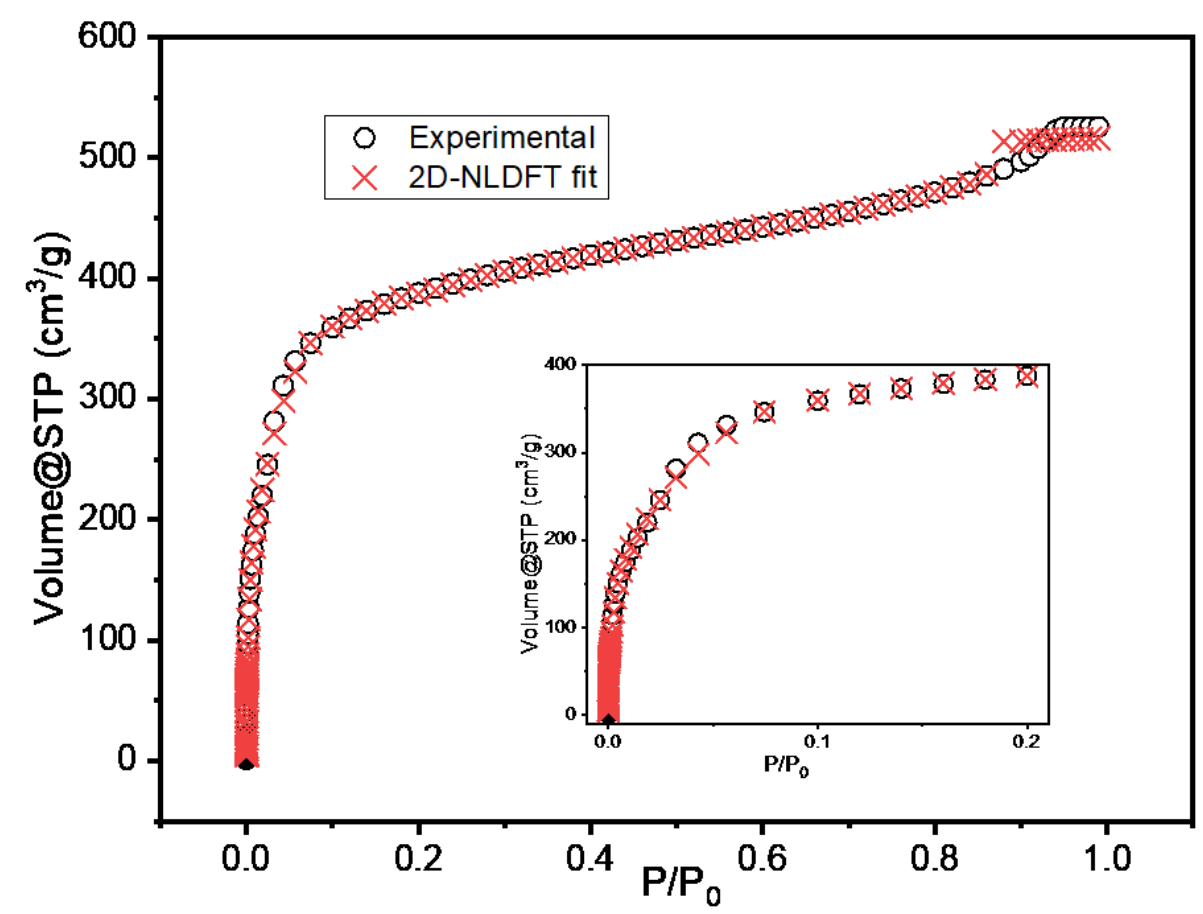

Figure S15. 2D-NLDFT model of Argon isotherm for IISERP-COF2 based on cylindrical pores in a MOF-1 surface. Insert shows the fitting at low pressure region between 0 and $0.2 \mathrm{P} / \mathrm{P}_{0}$. 


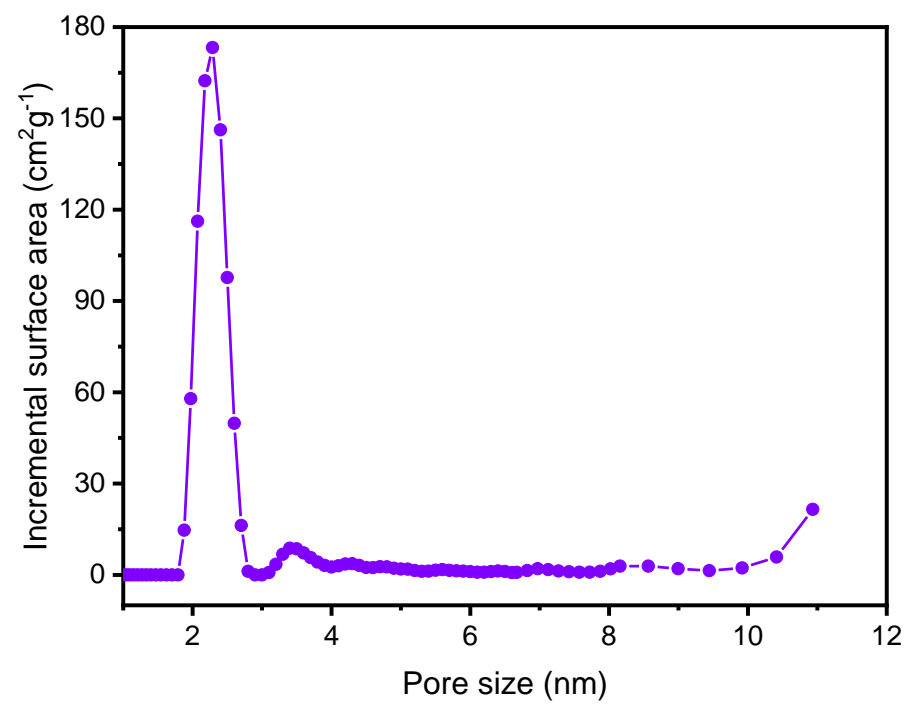

Figure S16. Full PSD of IISERP-COF2 synthesized by method 1 with freeze-pump-thaw and activated by flow of nitrogen activation method

$\underline{\mathrm{N}_{2}}$ sorption and Surface area measurement of IISERP-COF2 sample 2

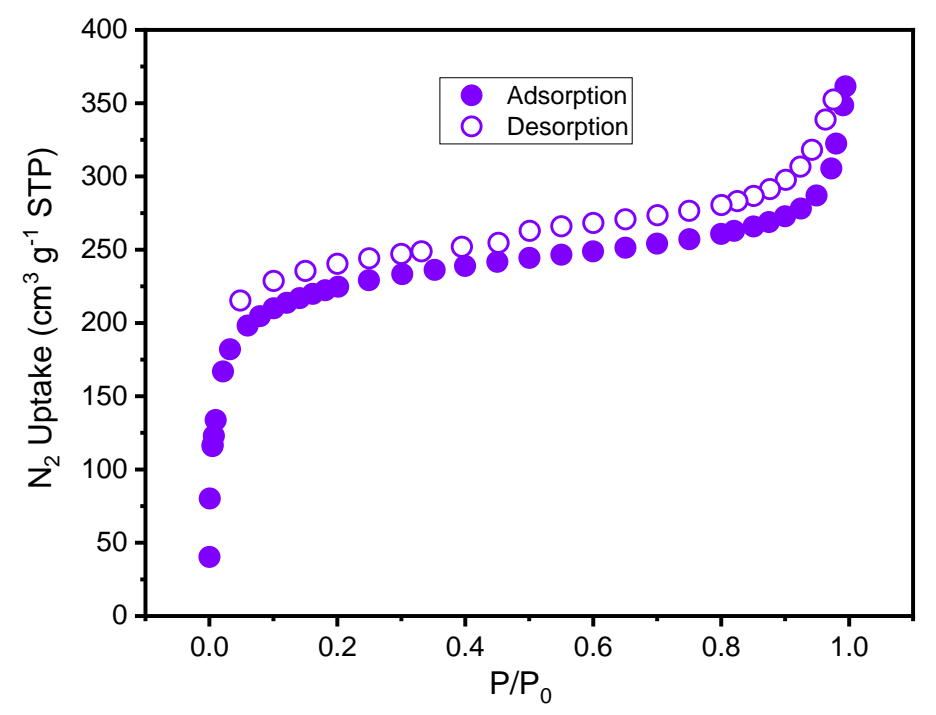

Figure S17. $\mathrm{N}_{2}$ sorption of IISERP-COF2 sample 2 synthesized by method 1 with freeze-pump-thaw and activated by heat activation method. Calculation of BET SA based on the isotherm gave the value of 851 $\mathrm{m}^{2} / \mathrm{g}$. 
$\underline{\mathrm{N}_{2}}$ sorption and Surface area measurement of IISERP-COF2 sample 3

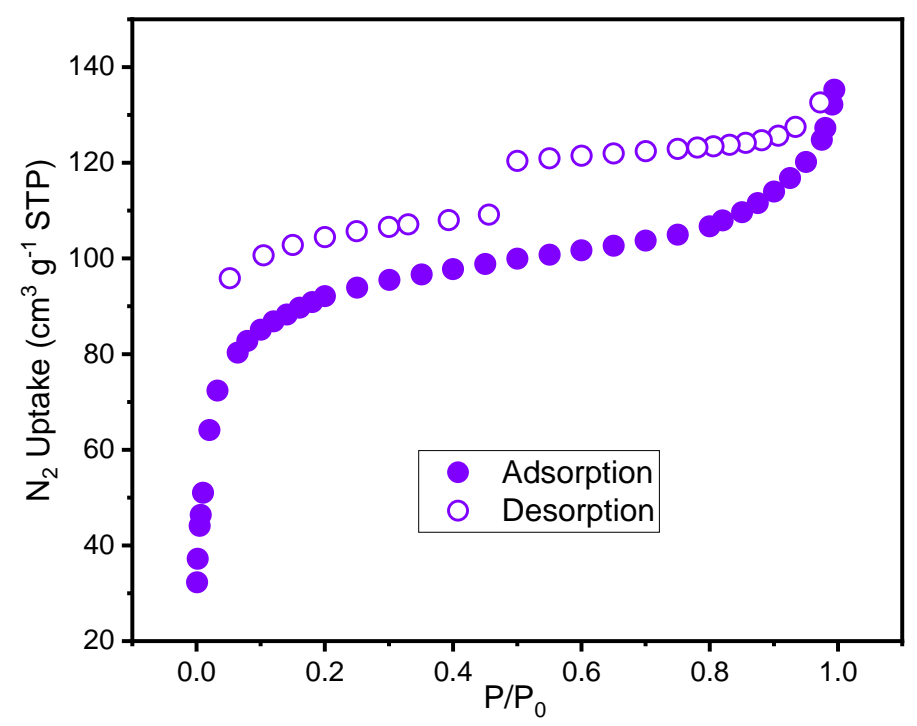

Figure S18. $\mathrm{N}_{2}$ sorption of IISERP-COF2 sample 3 synthesized by method 2 without pump-thaw and activated by heat activation method. Calculation of BET SA based on the isotherm gave the value of 343 $\mathrm{m}^{2} / \mathrm{g}$. 


\section{TEM}

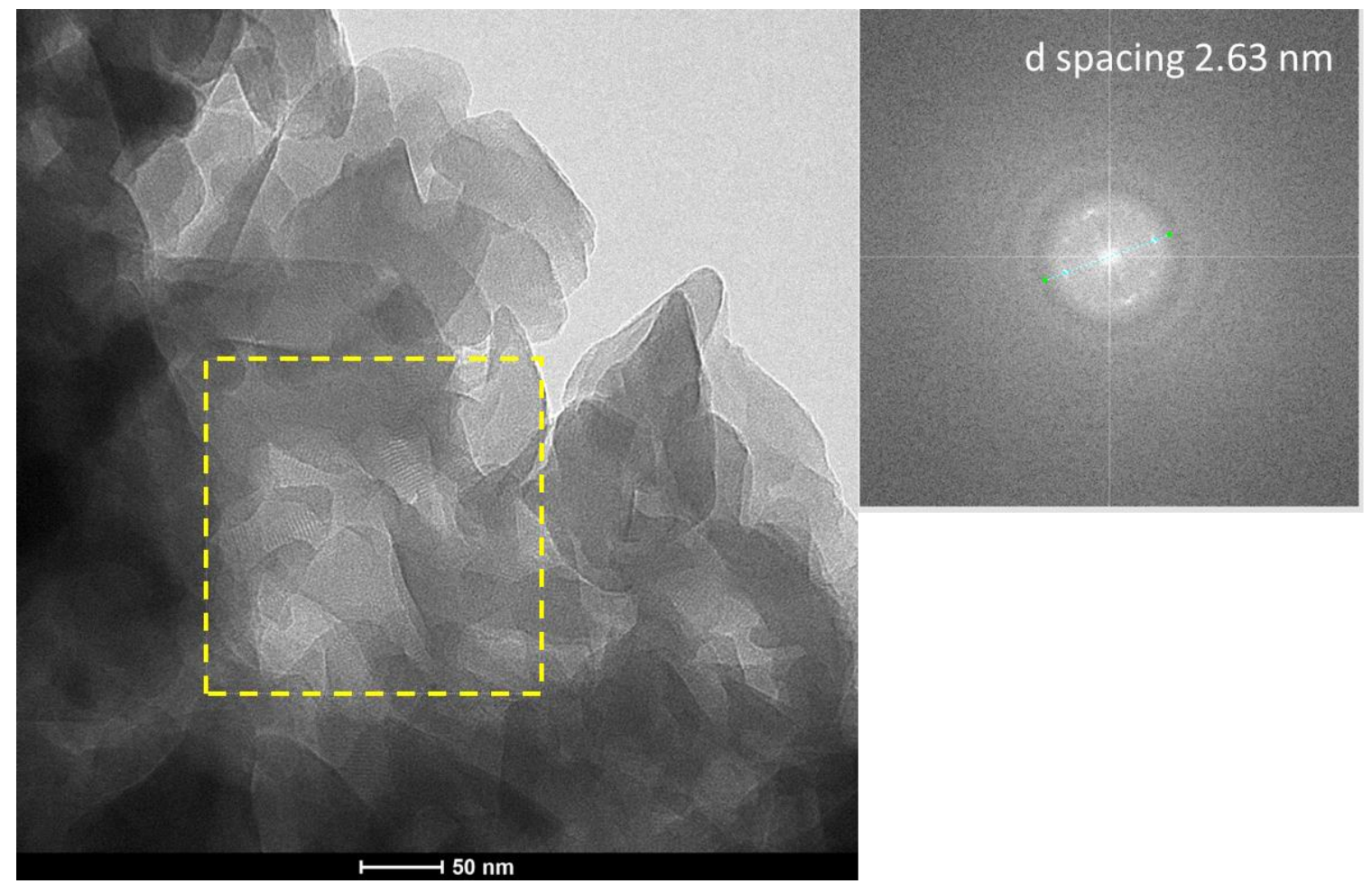

TEM

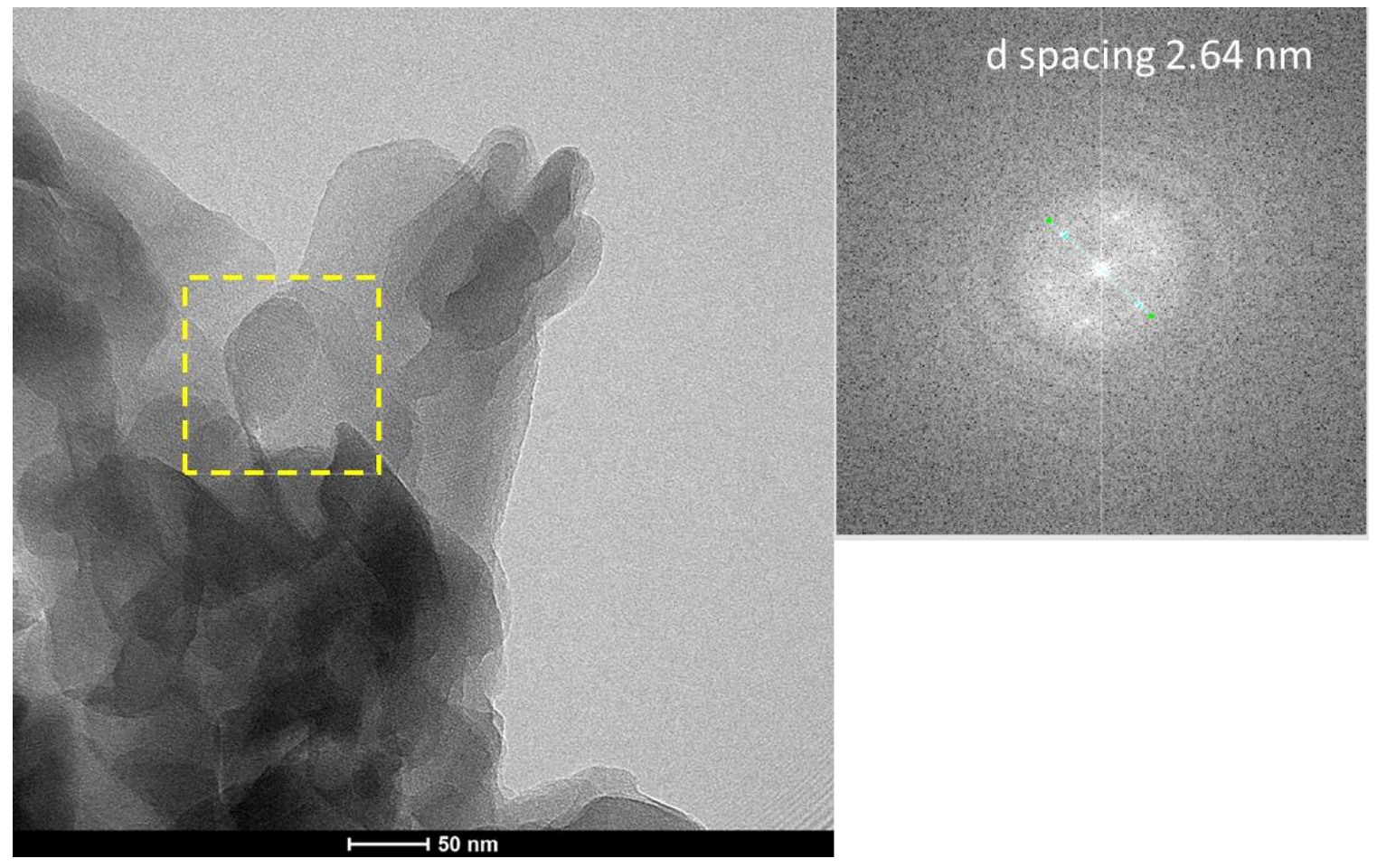

Figure S19. TEM images of TAPA-PDA COF at activated $(\beta)$ phase 


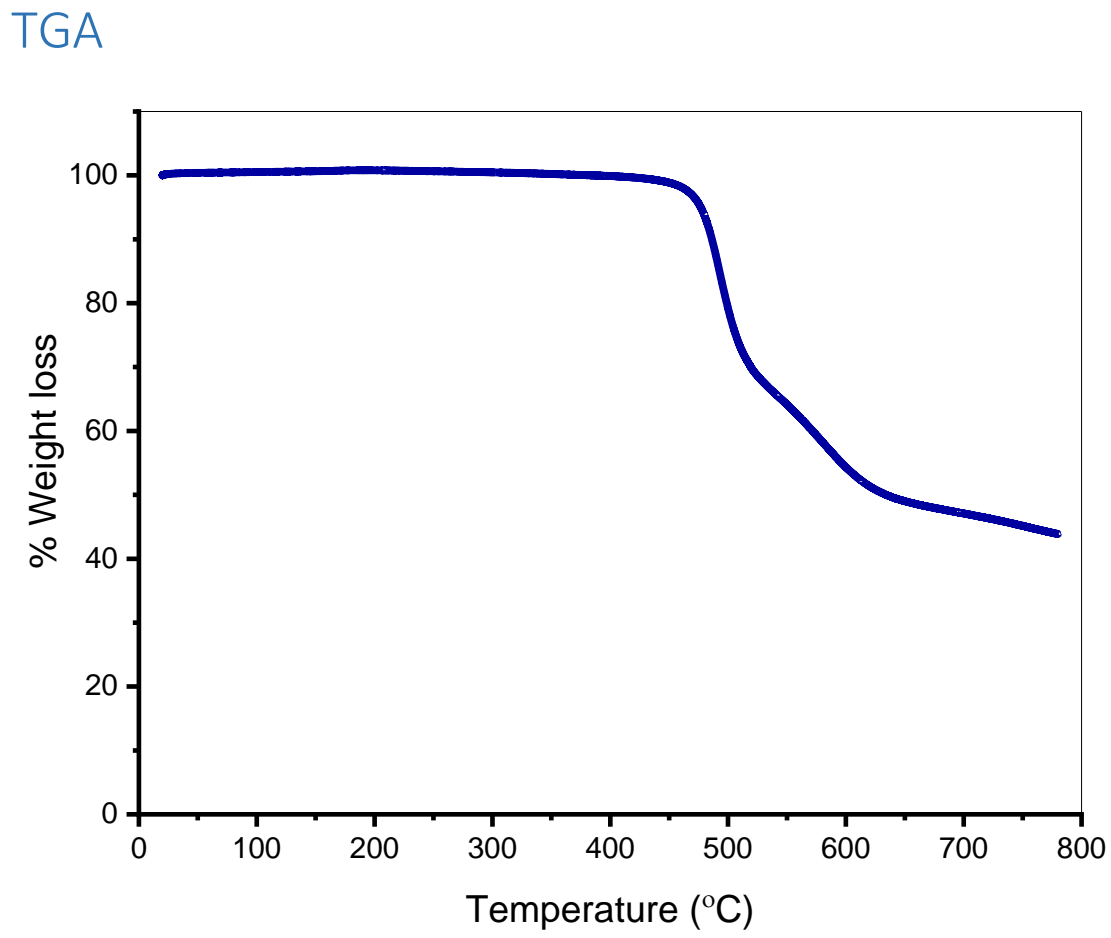

Figure S20. Thermogravimetric analysis of activated TAPA-PDA COF under a $\mathrm{N}_{2}$ atmosphere. 


\section{Phase reversibility study}

TAPA-PDA COF and IISERP COF2 were activated by flow of nitrogen method. After activation, the dry material was kept under high vacuum for 1 hour to make sure all solvents were removed. Activated materials ( $\beta$ phase) were then submerged in solvents: methanol, acetone, $n$-hexane and kept in these solvents until analysis. PXRD was obtained to identify the crystal phases of the material.

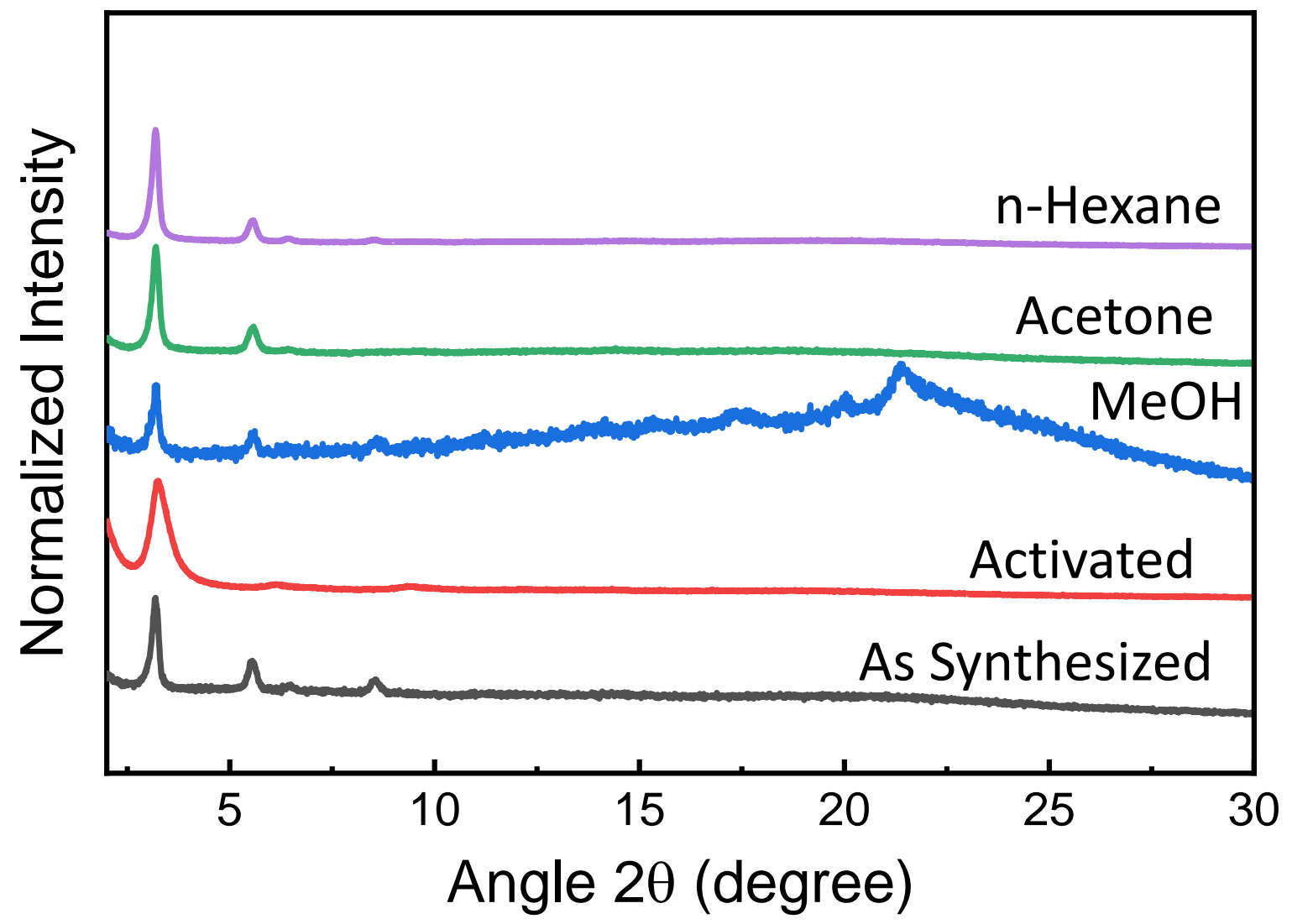

Figure S21. Phase reversibility study of TAPA-PDA COF. PXRD of as synthesized material was obtained from the COF suspension in acetone. 


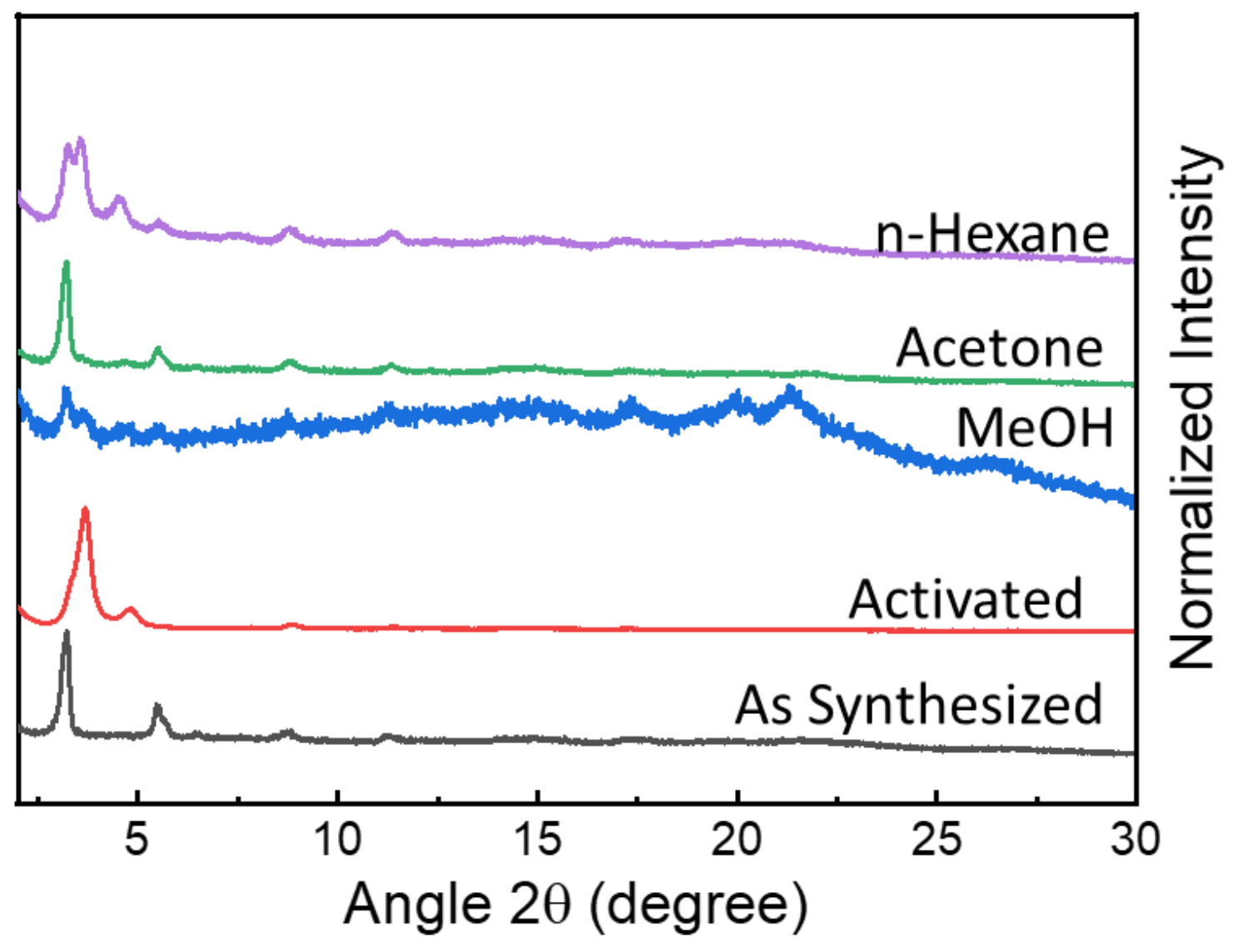

Figure S22. Phase reversibility study of IISERP-COF2. PXRD of as synthesized material was obtained from the COF suspension in acetone. 


\section{GIWAXS of thin films}

PXRD data of TAPA-PDA COF powder and IISERP-COF2 powder were converted from $2 \theta$ angle to $\mathrm{q}$ using the equation $q=\frac{4 \pi}{\lambda} \sin \left(\frac{2 \theta}{2}\right)$ where $\lambda$ is the wavelength of $\mathrm{Cu} K-\alpha 1.5406 \AA^{25,26}$

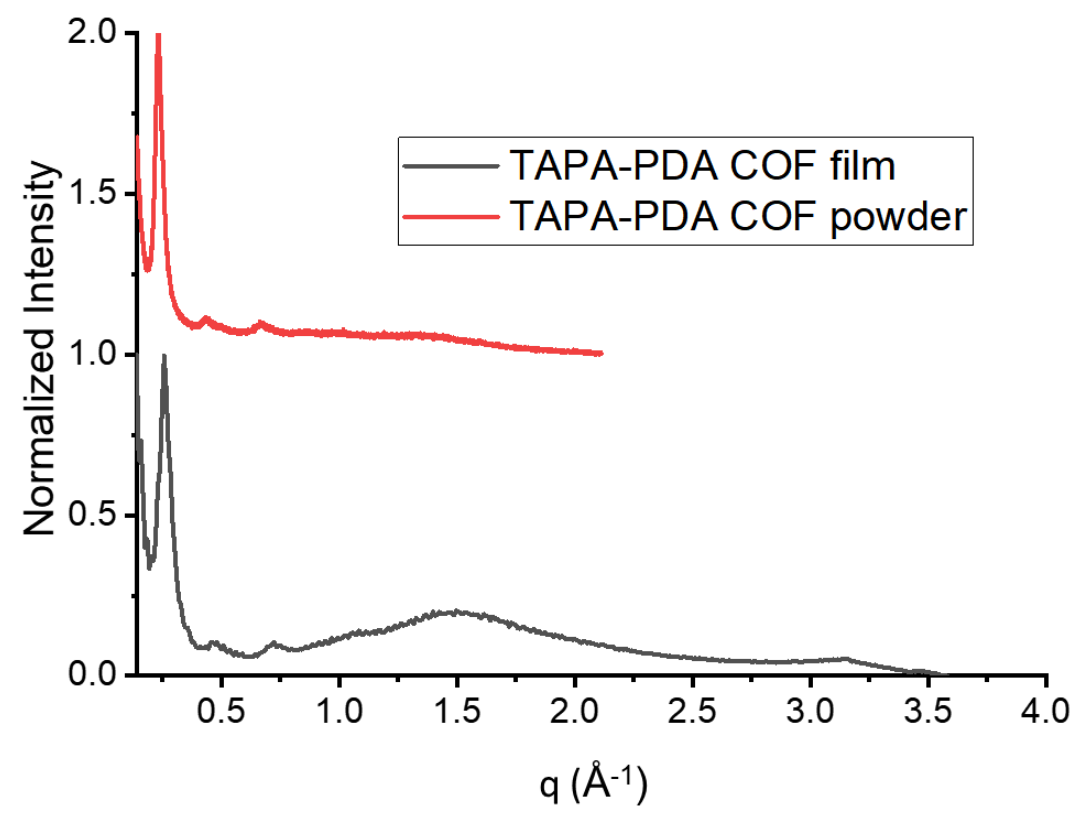

Figure S23. 1D projection of GIWAXS of TAPA-PDA COF film and PXRD pattern of TAPA-PDA Powder

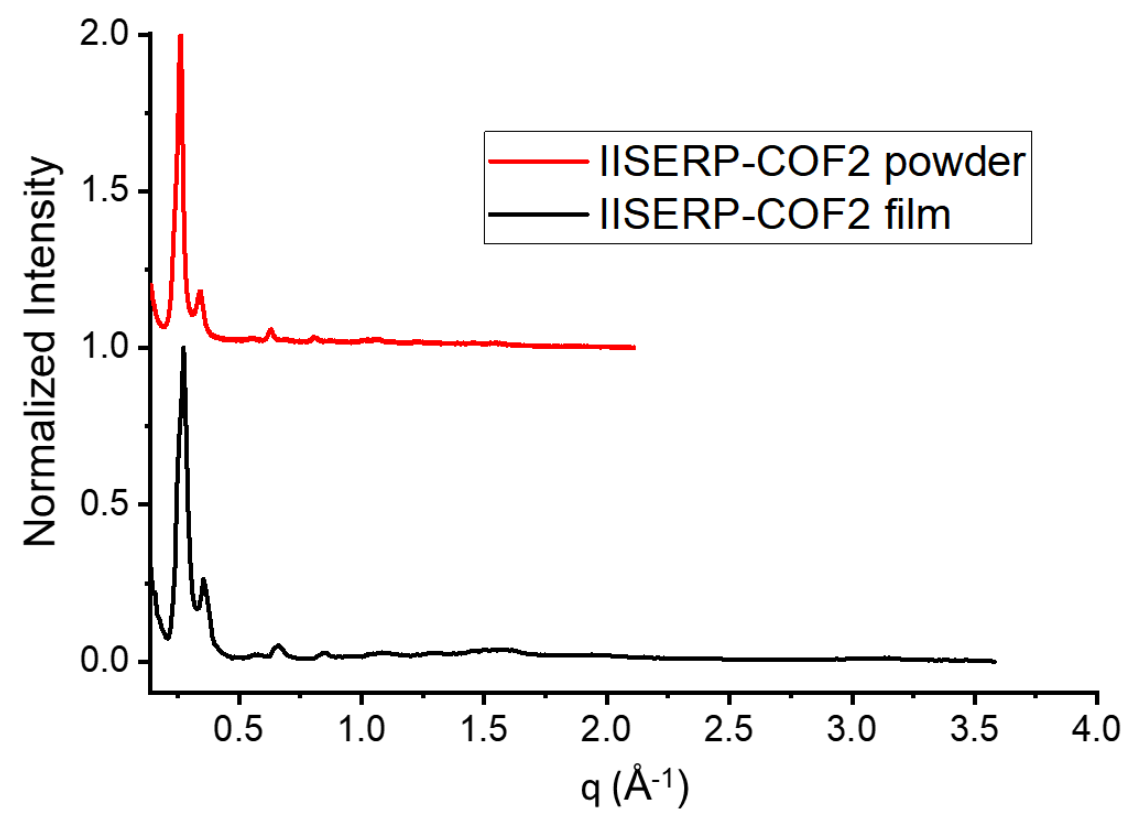

Figure S24. 1D projection of GIWAXS of IISERP-COF2 thin film and PXRD pattern of IISERP-COF2 powder 


\section{Solvatochromic}

TAPA-PDA COF and IISERP-COF2 solvent's response
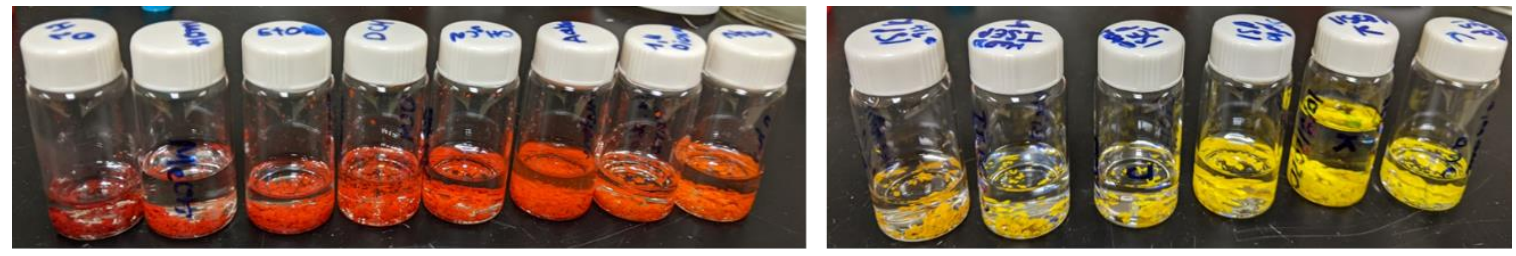

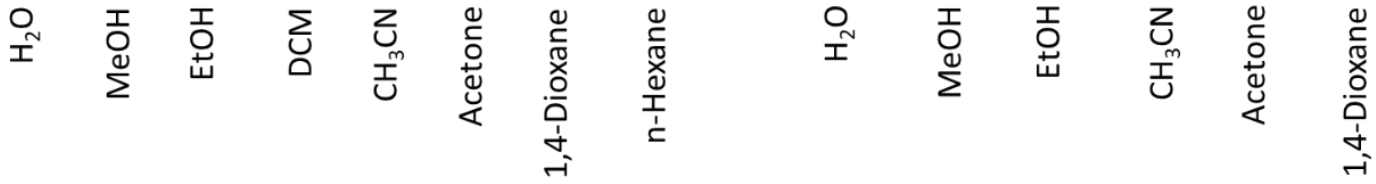

Figure S25. TAPA-PDA COF (orange - red) powder in solvents: n-hexane, 14-dioxane, acetone, acetonitrile, DCM, ethanol, methanol, and $\mathrm{H}_{2} \mathrm{O}$; IISERP-COF2 (yellow) in solvents 14-dioxane, acetone, acetonitrile, ethanol, methanol, and $\mathrm{H}_{2} \mathrm{O}$.

UV-Vis of TAPA-PDA COF film and IISERP-COF2 film in solvents

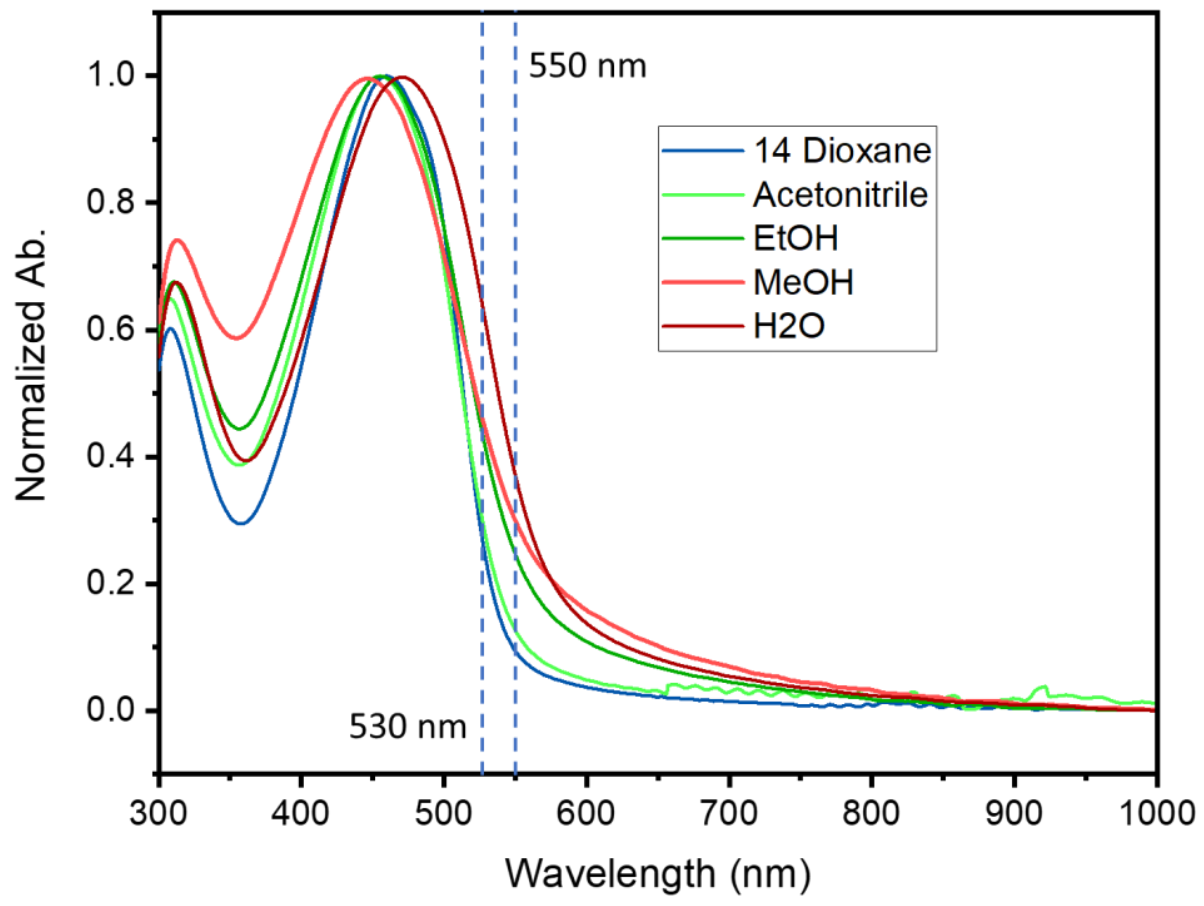

Figure S26. UV-Vis of TAPA-PDA COF thin films in various solvents with increasing polarity from 1,4Dioxane to $\mathrm{H}_{2} \mathrm{O}$ with highlighted 2 wavelengths of interest: $530 \mathrm{~nm}$ and $550 \mathrm{~nm}$ 


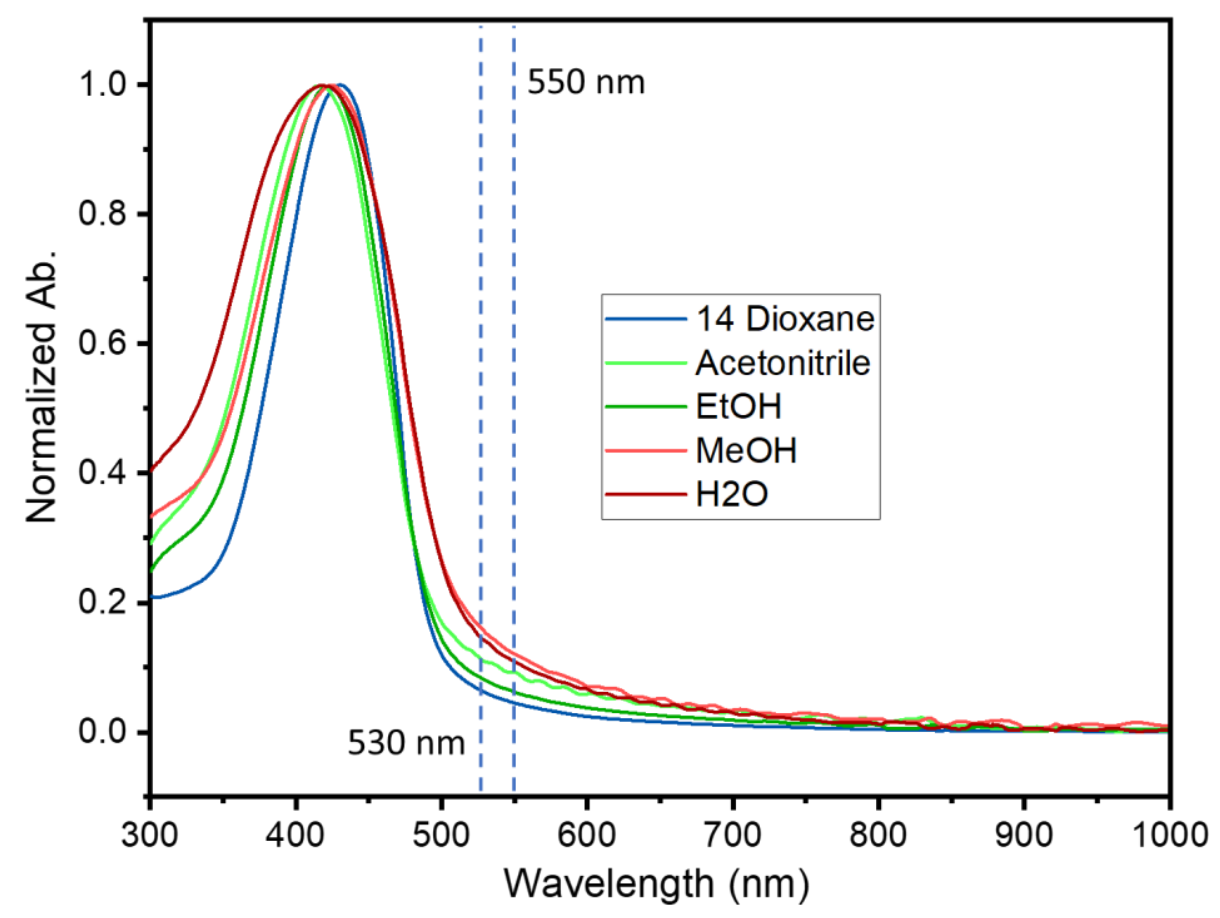

Figure S27. UV-Vis of IISERP-COF2 thin films in various solvents with increasing polarity from 1,4Dioxane to $\mathrm{H}_{2} \mathrm{O}$ with highlighted 2 wavelengths of interest: $530 \mathrm{~nm}$ and $550 \mathrm{~nm}$

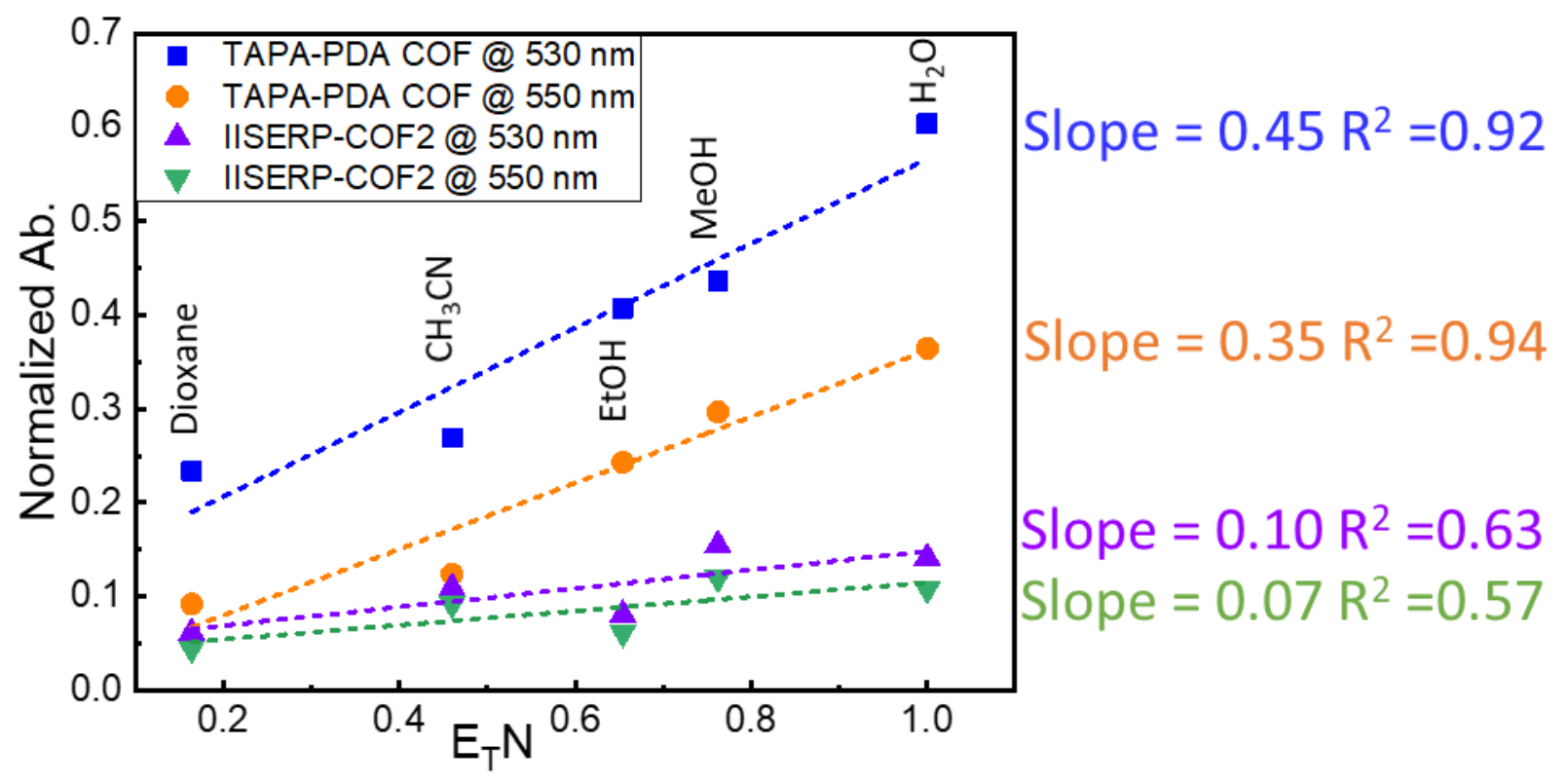

Figure S28. Normalized absorption of TAPA-PDA COF and IISERP-COF2 in various solvents at $530 \mathrm{~nm}$ and $550 \mathrm{~nm}$ vs solvents' polarity. 


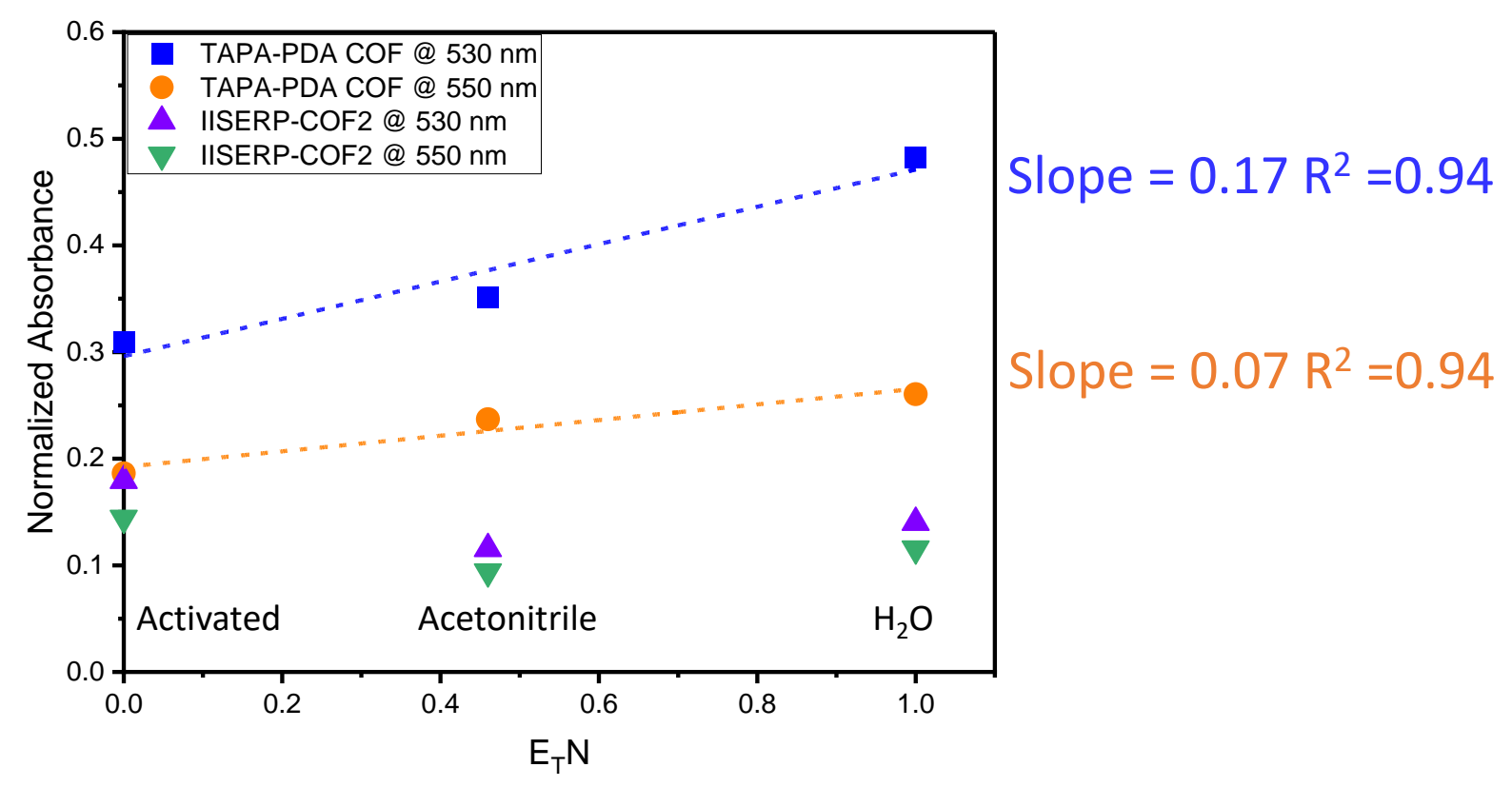

Figure S29. Normalized absorbance of TAPA-PDA COF and IISERP-COF2 in activated form and when the activated films were exposed to acetonitrile and water at $530 \mathrm{~nm}$ and $550 \mathrm{~nm}$.

\section{$\underline{\text { UV-Vis Spectra of COF-analogs }}$}

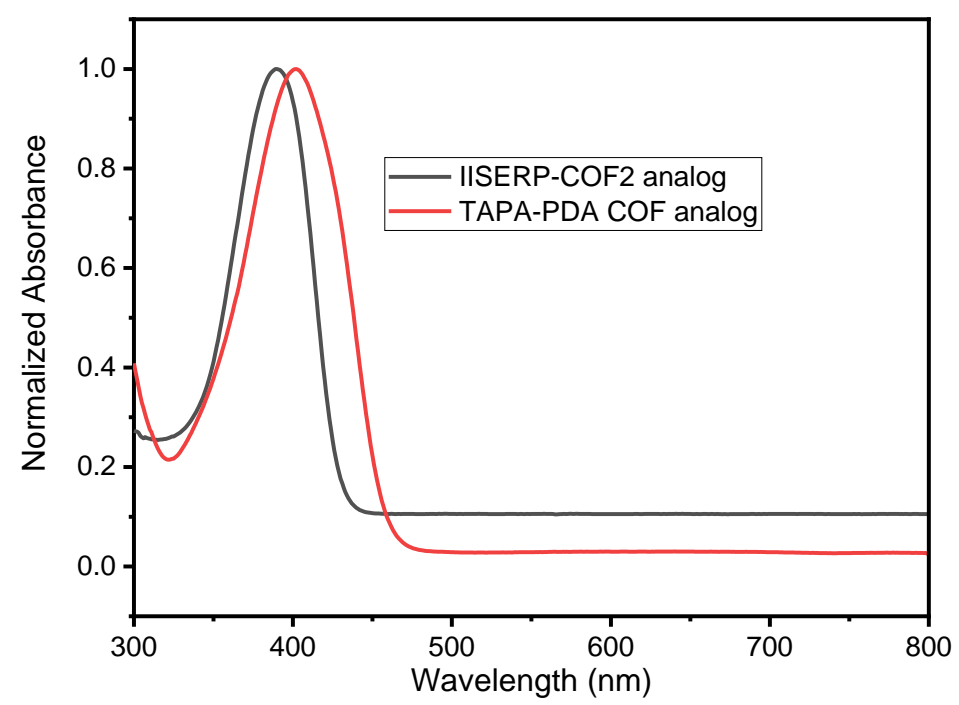

Figure S30. UV-Vis spectra of TAPA-PDA COF analog and IISERP-CO2 analog in THF. TAPA-PDA COF analog has UV-Vis absorption at $402 \mathrm{~nm}$, IISERP-COF2 analog has UV-Vis absorption at $390 \mathrm{~nm}$. 
$\underline{\text { UV-Vis in different solvents }}$

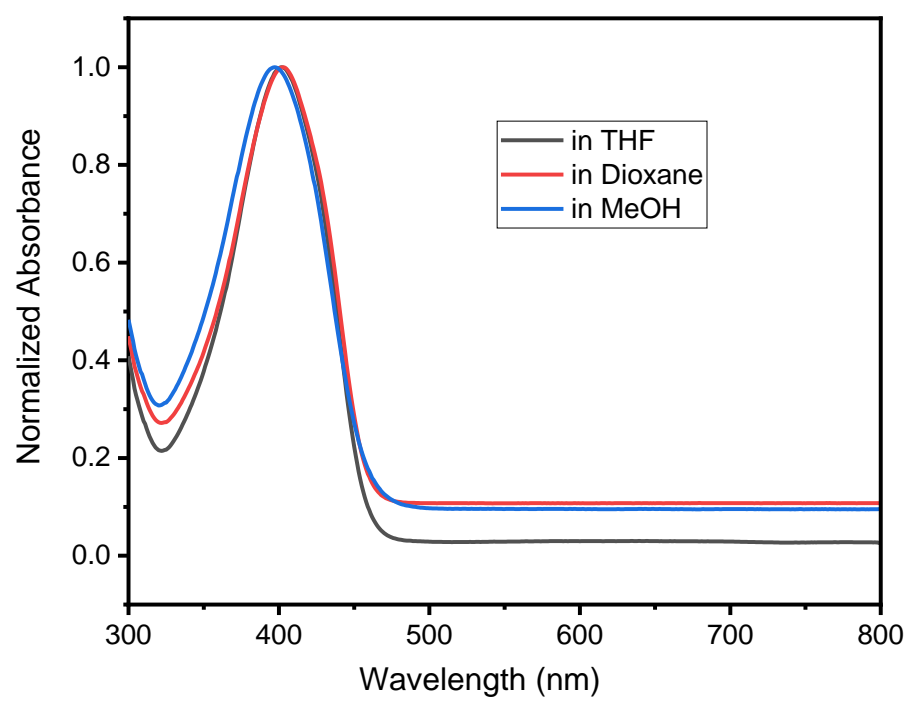

Figure S31. UV-Vis spectra of TAPA-PDA analog in various solvents (THF 402 nm, 1,4-Dioxane 403 $\mathrm{nm}, \mathrm{MeOH} 397 \mathrm{~nm}$ )

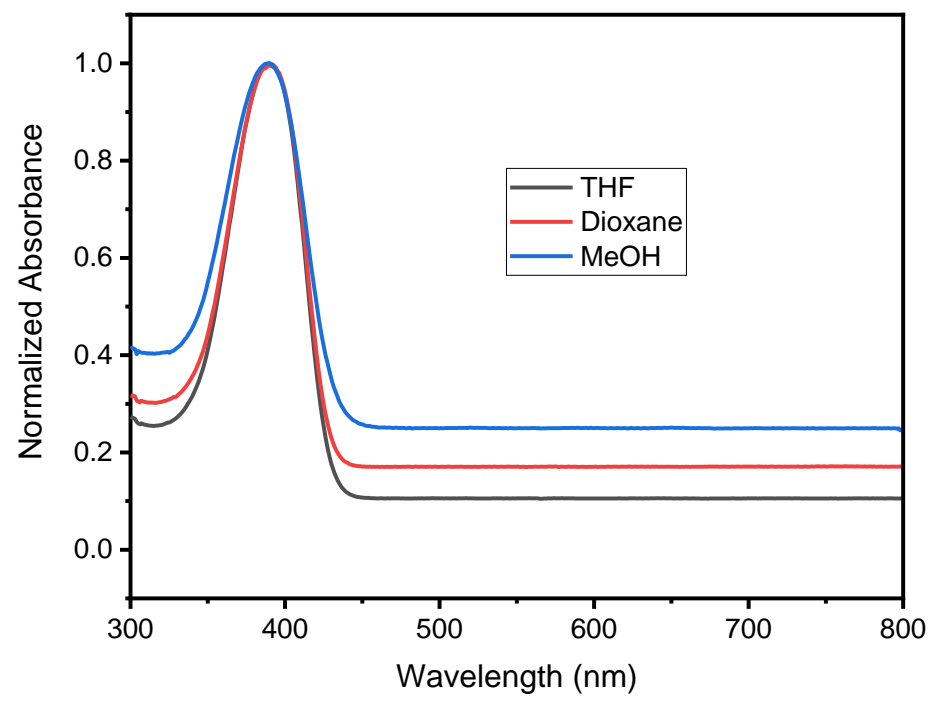

Figure S32. UV-Vis spectra of IISERP-COF2 analog in various solvents (THF $390 \mathrm{~nm}, 1,4-$ Dioxane 390 $\mathrm{nm}, \mathrm{MeOH} 389 \mathrm{~nm}$ ) 


\section{Fluorescence of COF analog}

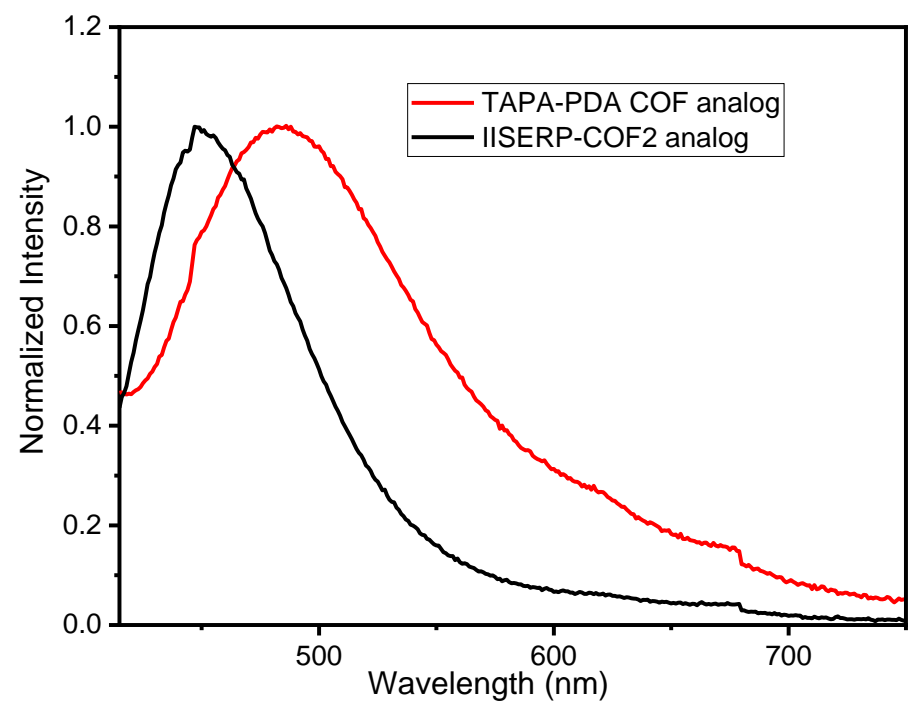

Figure S33. FL spectra of TAPA-PDA COF analog (red line, emission maximum $488 \mathrm{~nm}$, excitation at $350 \mathrm{~nm}$ ) and IISERP-COF2 analog (black line, emission maximum $447 \mathrm{~nm}$, excitation at $350 \mathrm{~nm}$ ) in THF

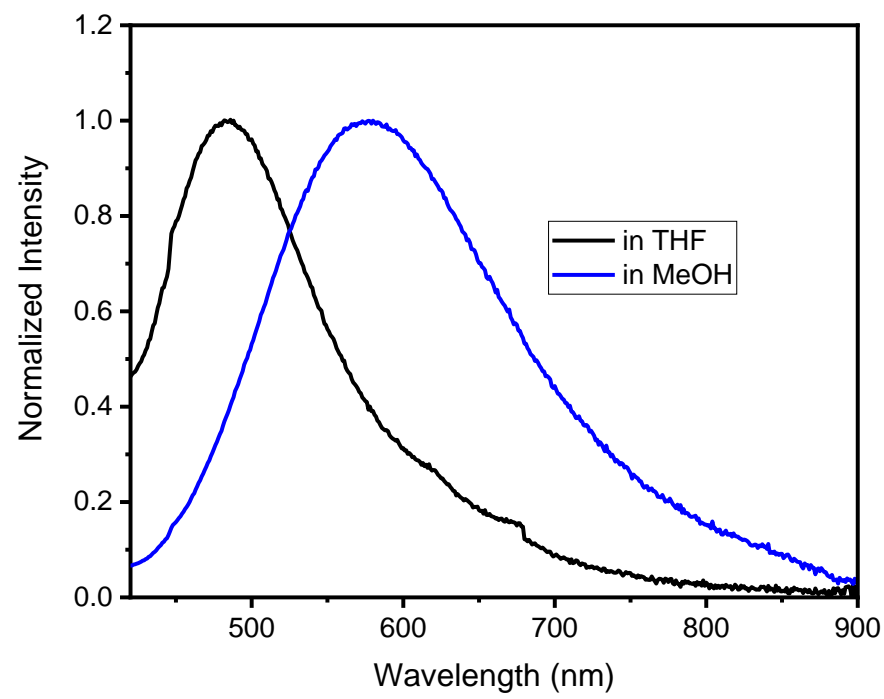

Figure S34. FL spectra of TAPA-PDA COF analog in various solvents (Emission max in THF $488 \mathrm{~nm}$, $\mathrm{MeOH} 580 \mathrm{~nm}$ ) with excitation at $350 \mathrm{~nm}$ 


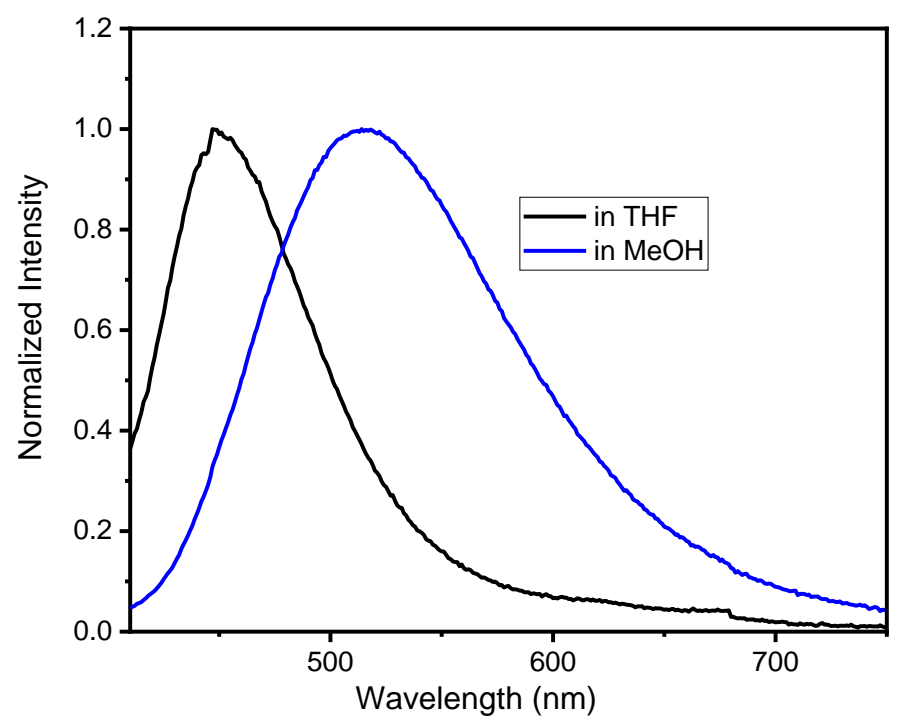

Figure S35. FL spectra of IISERP-COF2 analog in various solvents (Emission max in THF $447 \mathrm{~nm}$, $\mathrm{MeOH} 514 \mathrm{~nm}$ ) with excitation at $350 \mathrm{~nm}$

\section{Surface energy}

Contact angle measurement

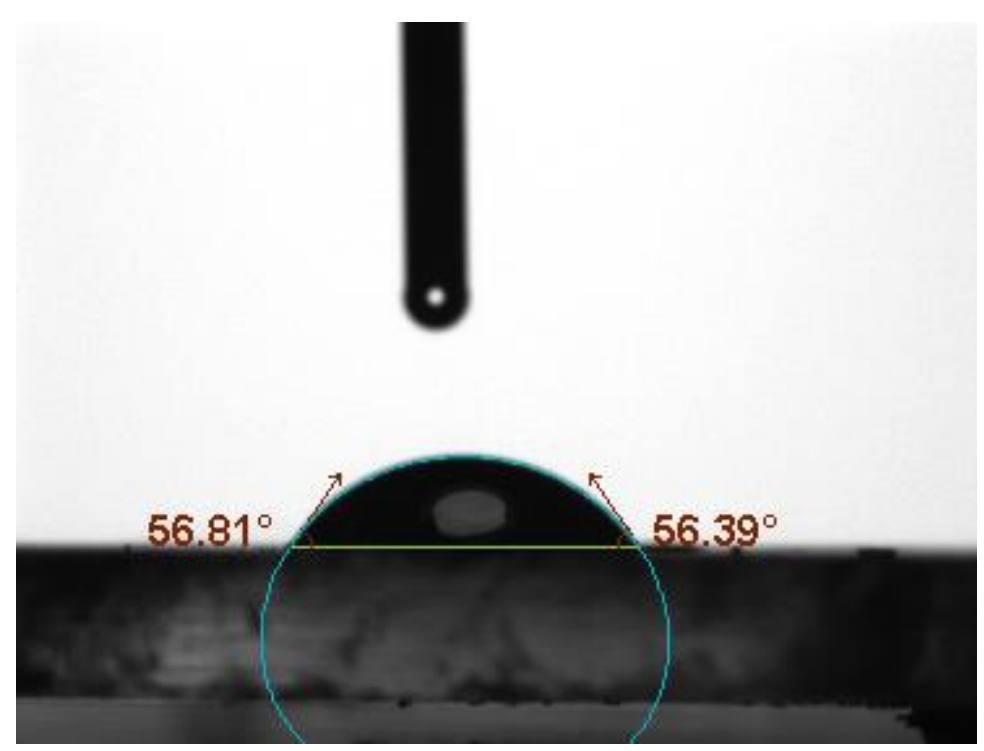

Figure S36. Contact angle measurement of TAPA-PDA COF films

On average $57 \pm 2^{\circ}$ 
Contact angle measurement of IISERP-COF2 and TAPA-PDA COF powder materials

Table S4. List of IISERP-COF2 samples prepared and activated by different methods and their properties

\begin{tabular}{|l|l|l|l|l|}
\hline Sample & Method of synthesis & $\begin{array}{l}\text { Method of } \\
\text { activation }\end{array}$ & BET & Contact angle \\
\hline $\begin{array}{l}\text { IISERP-COF2 } \\
\text { sample 1 }\end{array}$ & $\begin{array}{l}\text { Method 1 } \\
\text { (freeze-pump-thaw) }\end{array}$ & $\begin{array}{l}\text { Flow of N } \\
\text { activation }\end{array}$ & $1359 \mathrm{~m}^{2} / \mathrm{g}$ & Hydrophilic \\
\hline $\begin{array}{l}\text { IISERP-COF2 } \\
\text { sample 2 }\end{array}$ & $\begin{array}{l}\text { Method 1 } \\
\text { (freeze-pump-thaw) }\end{array}$ & $\begin{array}{l}\text { Activation by } \\
\text { heat }\end{array}$ & $851 \mathrm{~m}^{2} / \mathrm{g}$ & Hydrophilic \\
\hline $\begin{array}{l}\text { IISERP-COF2 } \\
\text { sample 3 }\end{array}$ & $\begin{array}{l}\text { Method 2 } \\
\text { (only freeze) }\end{array}$ & $\begin{array}{l}\text { Activation by } \\
\text { heat }\end{array}$ & $343 \mathrm{~m}^{2} / \mathrm{g}$ & $126^{\circ} \pm 3^{\circ}$ \\
\hline
\end{tabular}

\section{Additional Studies on IISERP-COF2 synthesis and activation}

Synthesis of IISERP-COF2 using Method 2 (only freeze, no pump-thaw step): IISERP-COF2 was synthesized followed the reported procedure with a small modification. ${ }^{17,18}$ To a $35 \mathrm{ml}$ pressure vessel equipped with a stirrer was added tris(4-formylphenyl) amine (30 mg, $0.09 \mathrm{mmol}$ ), 1,4-diaminobenzene $(15 \mathrm{mg}, 0.14 \mathrm{mmol})$ and ethanol $(1.125 \mathrm{ml})$. The resulting mixture was stirred at RT for $15 \mathrm{mins}$. Dichlorobenzene $(1.125 \mathrm{ml})$ was then added and stirring was continued for 15 mins. The solution was then bubbled with $\mathrm{N}_{2}$ for 10 mins. Acetic acid (3M, $0.094 \mathrm{ml}$ ) was added followed by a quick $\mathrm{N}_{2}$ bubbling through the solution $(30 \mathrm{~s})$. The resulting mixture was rapidly frozen to $77 \mathrm{~K}$ by liquid nitrogen, sealed and heated at $120{ }^{\circ} \mathrm{C}$ for 3 days. After completion, reaction mixture was cooled down to RT and a yellow solid product was obtained.

Activation of IISERP-COF2 by heat: Product was washed with copious amount of DMF, 1,4-Dioxane, methanol, acetone, THF. THF was removed and the material was heated to $70{ }^{\circ} \mathrm{C}$ for 4 hours to generate the dry, activated product.

Using freeze-pump-thaw synthesis method (Method 1) and heat activation method gave $33.2 \mathrm{mg}$ of the product ( $83 \%$ yield).

Using Method 2 of synthesis and heat activation method gave $29.2 \mathrm{mg}$ of the product (73\% yield).

Contact angle measurement TAPA-PDA COF powder and IISERP-COF2 samples prepared by different methods

Activated COFs are very powdery and exhibited high degrees of static. As a consequence, to measure contact angle of powder sample, double sided tape was used to fix the material into a glass slide. COF powders were packed and fully covered the area of the double sided tape (Figure S37)

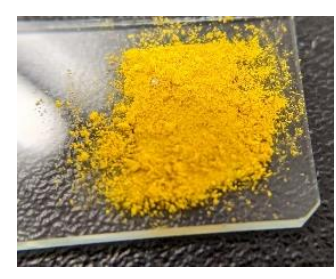

Figure S37. IISERP-COF2 sample 3 for contact angle measurement 

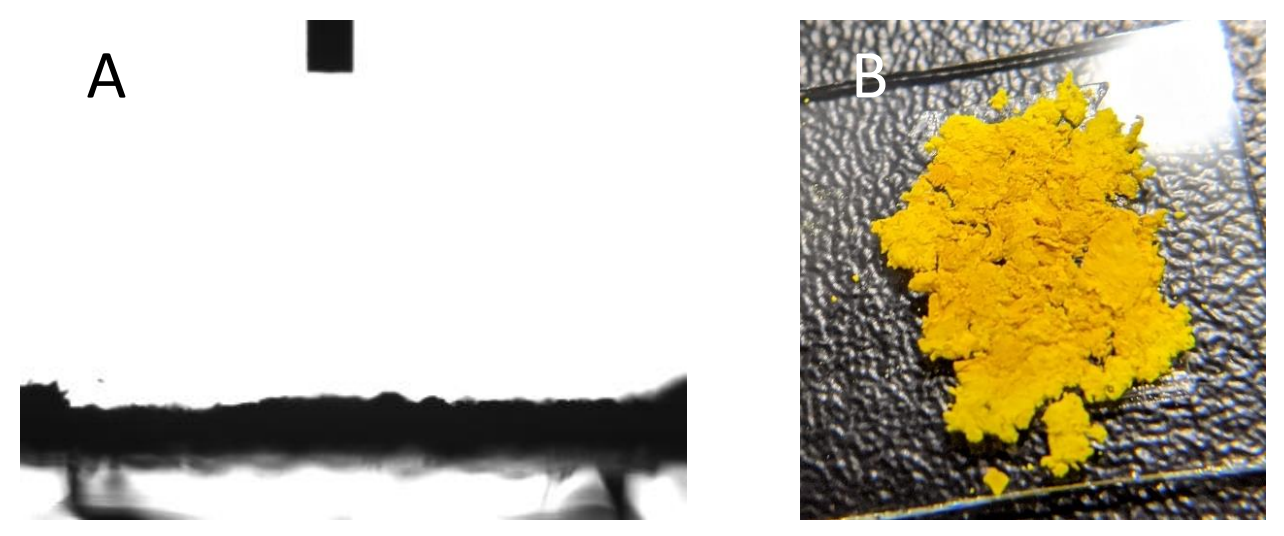

Figure S38. Contact angle measurement of IISERP-COF2 sample 1. A) Picture from the tensiometer showing the material absorbed the water droplet. B) Picture of IISERP-COF2 sample 1 after the test.
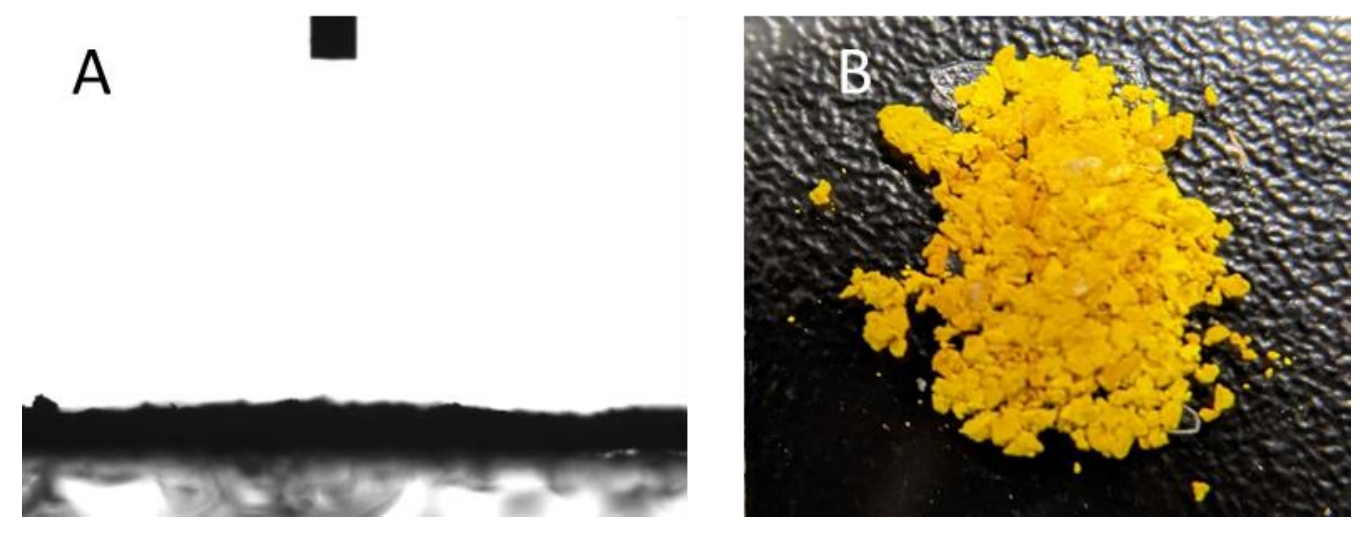

Figure S39. Contact angle measurement of IISERP-COF2 sample 2. A) Picture from the tensiometer showing the material absorbed the water droplet. B) Picture of IISERP-COF2 sample 2 after the test.
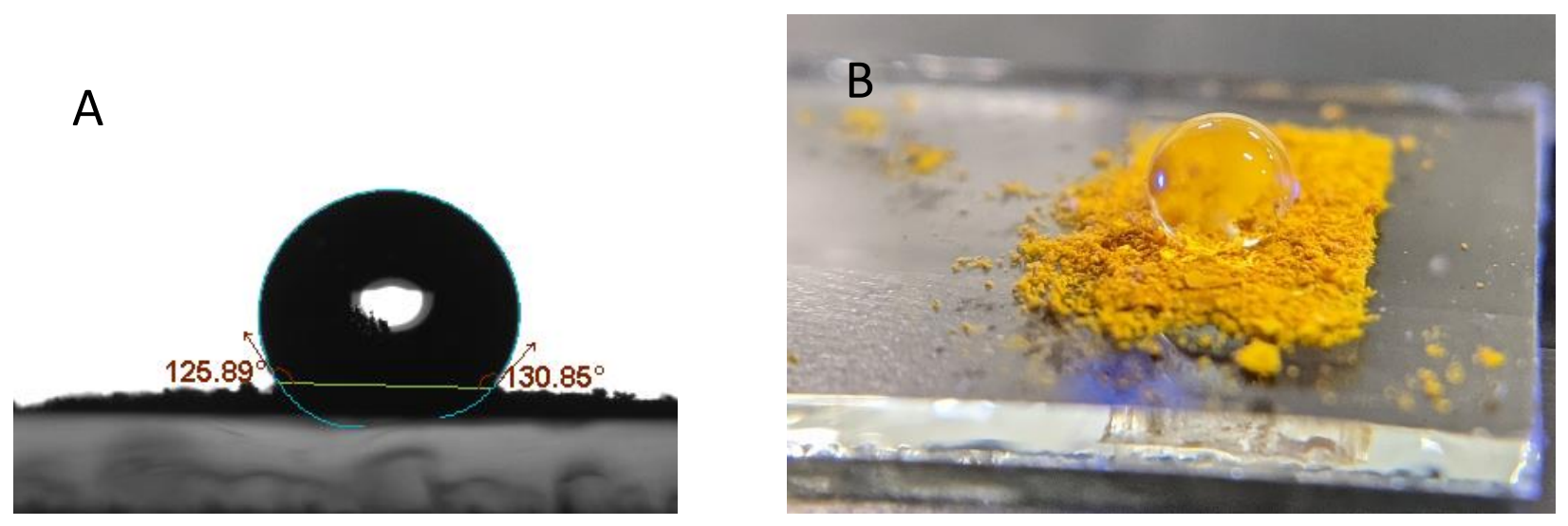

Figure S40. Contact angle measurement of IISERP-COF2 sample 3. A) Picture from the tensiometer showing the material is hydrophobic. B) Picture of IISERP-COF2 sample 3 after the test with the water droplet on the hydrophobic surface.

On average, the contact angle is $126^{\circ} \pm 3^{\circ}$ 


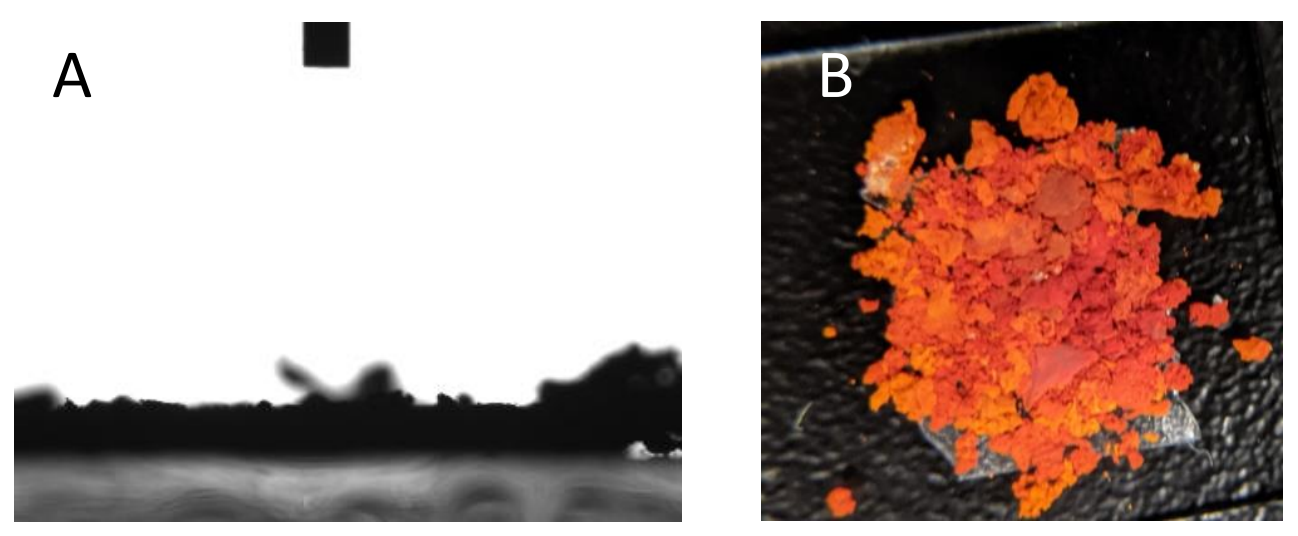

Figure S41. Contact angle measurement of TAPA-PDA COF. A) Picture from the tensiometer showing the material absorbed the water droplet. B) Picture of TAPA-PDA COF after the test.

\section{NMR and HRMS Spectra}

\section{${ }^{1} \mathrm{H}$ NMR of TAPA-PDA COF analog (below)}

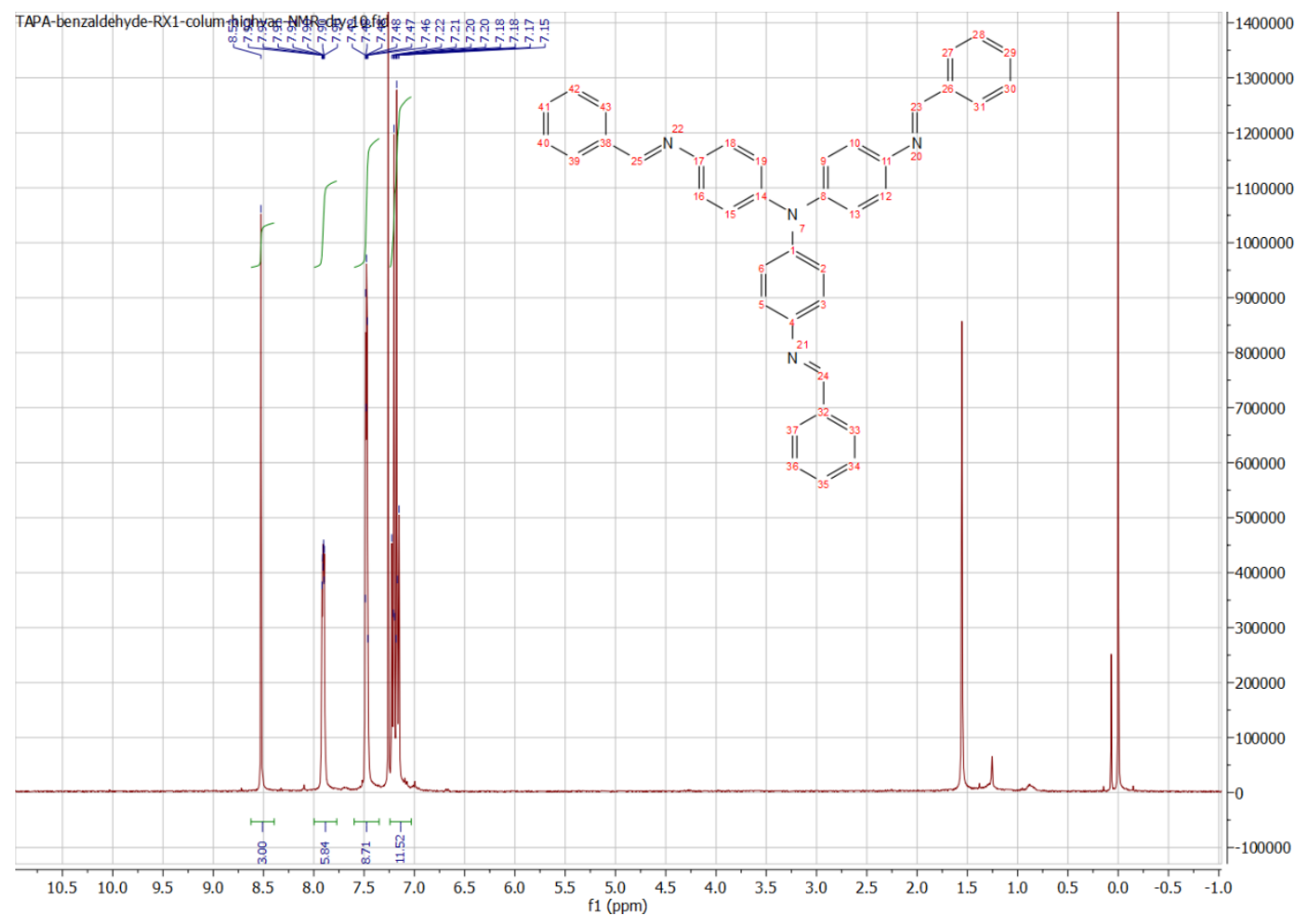


${ }^{13} \mathrm{C}$ NMR of TAPA-PDA COF analog (below)

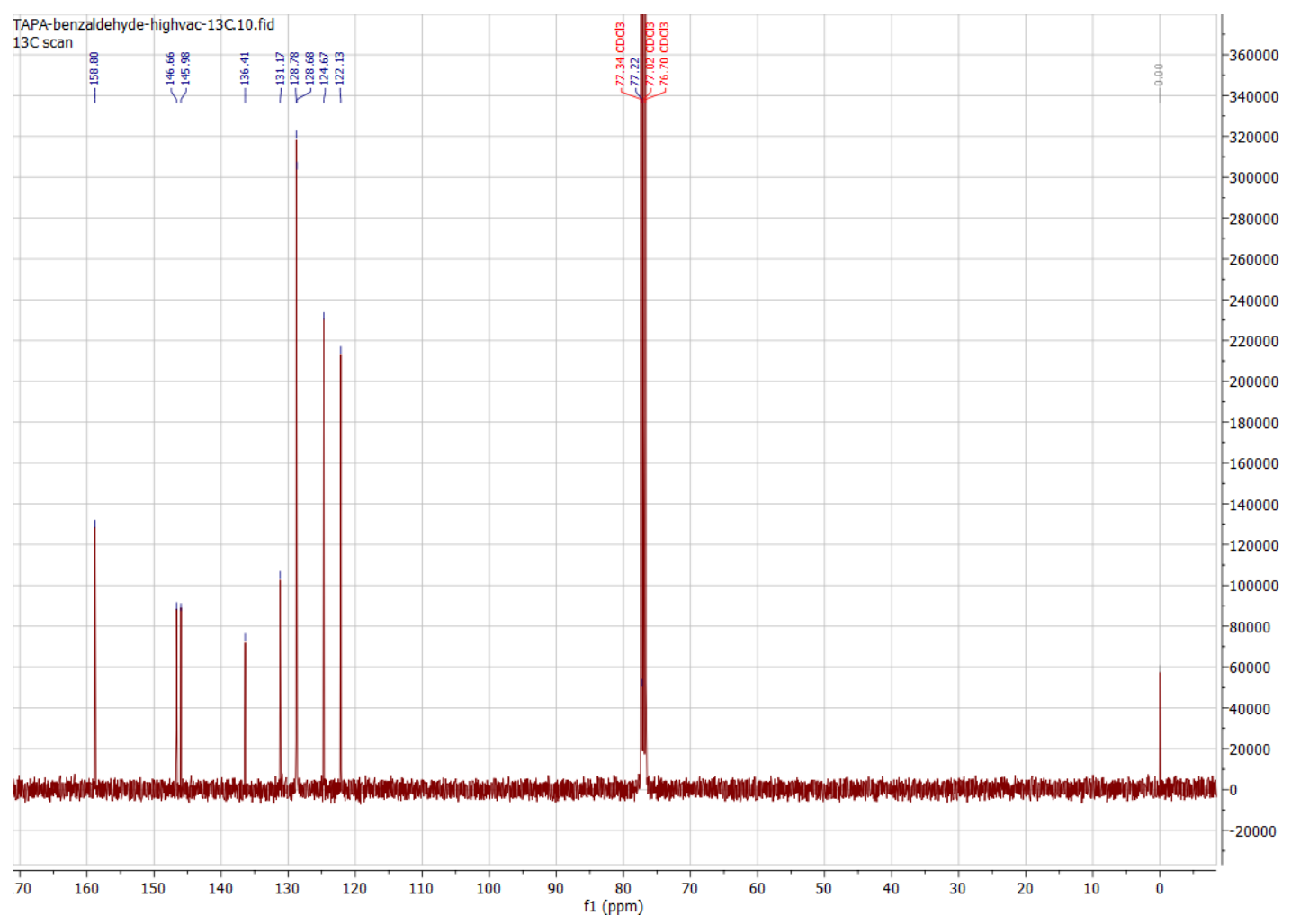

ESI + for TAPA-PDA COF analog (below)

50022 Ly \#11-124 RT: $0.08-0.98$ AV: 114 NL: 3.11 E7
T: FTMS + c ESI Full ms [100.00-1200.00]

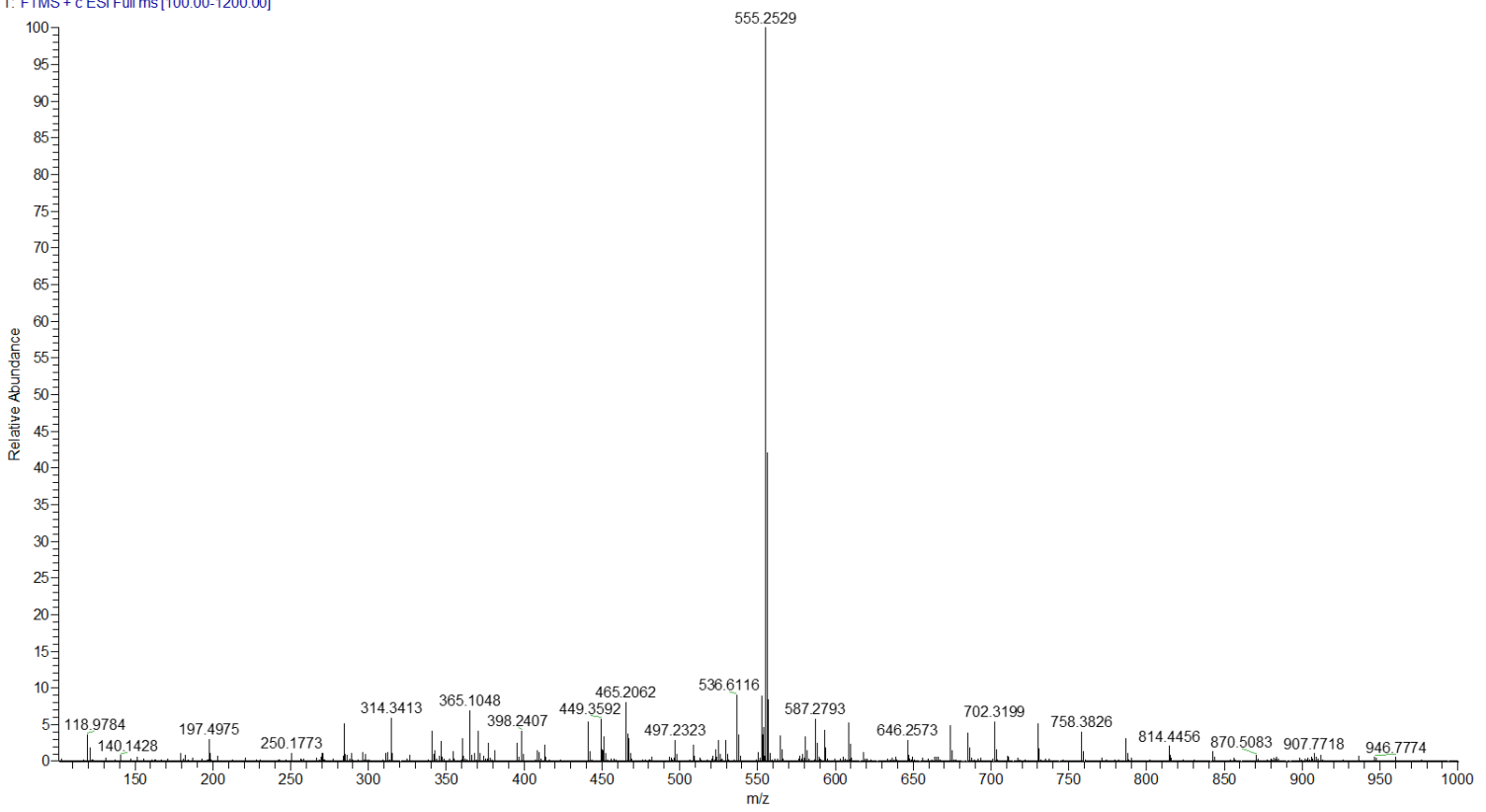

36 
${ }^{1} \mathrm{H}$ NMR of IISERP-COF2 analog (below)

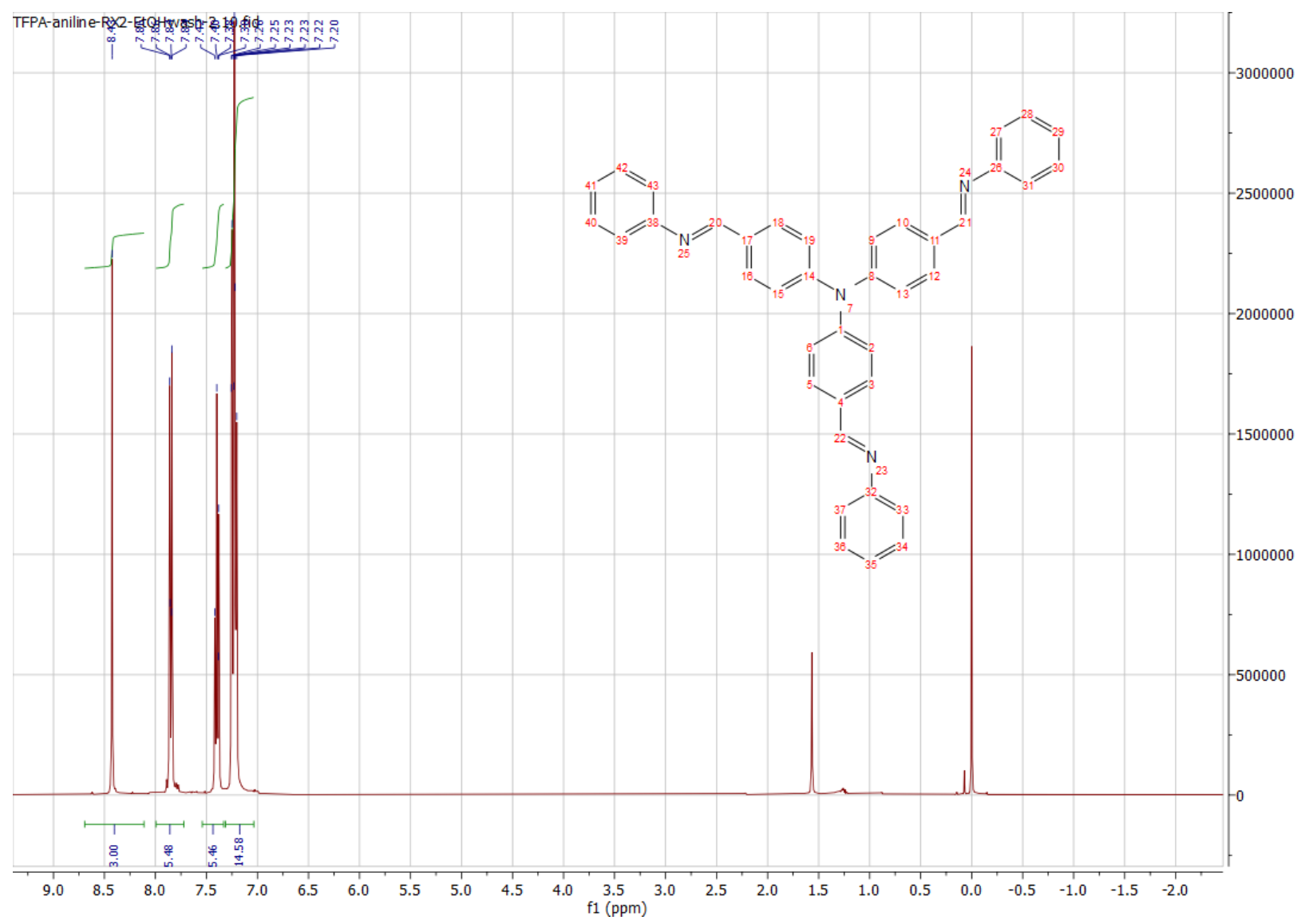

\section{References}

(1) Liu, H.; Li, C.; Li, H.; Ren, Y.; Chen, J.; Tang, J.; Yang, Q. Structural Engineering of Two-Dimensional Covalent Organic Frameworks for Visible-Light-Driven Organic Transformations. ACS Appl. Mater. Interfaces 2020, 12 (18), 20354-20365. https://doi.org/10.1021/acsami.0c00013.

(2) Patra, B. C.; Das, S. K.; Ghosh, A.; Raj K, A.; Moitra, P.; Addicoat, M.; Mitra, S.; Bhaumik, A.; Bhattacharya, S.; Pradhan, A. Covalent Organic Framework Based Microspheres as an Anode Material for Rechargeable Sodium Batteries. J. Mater. Chem. A 2018, 6 (34), 16655-16663. https://doi.org/10.1039/C8TA04611E.

(3) He, S.; Yin, B.; Niu, H.; Cai, Y. Targeted Synthesis of Visible-Light-Driven Covalent Organic Framework Photocatalyst via Molecular Design and Precise Construction. Appl. Catal. B Environ. 2018, 239, 147-153. https://doi.org/https://doi.org/10.1016/j.apcatb.2018.08.005.

(4) Haase, F.; Gottschling, K.; Stegbauer, L.; Germann, L. S.; Gutzler, R.; Duppel, V.; Vyas, V. S.; Kern, K.; Dinnebier, R. E.; Lotsch, B. V. Tuning the Stacking Behaviour of a 2D Covalent Organic Framework through Non-Covalent Interactions. Mater. Chem. Front. 2017, 1 (7), 1354-1361. https://doi.org/10.1039/C6QM00378H. 
(5) Yang, M.; Mo, C.; Fang, L.; Li, J.; Yuan, Z.; Chen, Z.; Jiang, Q.; Chen, X.; Yu, D. Multibranched Octupolar Module Embedded Covalent Organic Frameworks Enable Efficient Two-Photon Fluorescence. Adv. Funct. Mater. 2020, 30 (34), 2000516. https://doi.org/https://doi.org/10.1002/adfm.202000516.

(6) Feriante, C. H.; Jhulki, S.; Evans, A. M.; Dasari, R. R.; Slicker, K.; Dichtel, W. R.; Marder, S. R. Rapid Synthesis of High Surface Area Imine-Linked 2D Covalent Organic Frameworks by Avoiding Pore Collapse During Isolation. Adv. Mater. 2020, 32 (2), 1905776. https://doi.org/https://doi.org/10.1002/adma.201905776.

(7) Song, J.-R.; Sun, J.; Liu, J.; Huang, Z.-T.; Zheng, Q.-Y. Thermally/Hydrolytically Stable Covalent Organic Frameworks from a Rigid Macrocyclic Host. Chem. Commun. 2014, 50 (7), 788-791. https://doi.org/10.1039/C3CC47652A.

(8) Zhen, J.; Ding, S.; Liu, J.; Huang, Z.; Wang, W.; Zheng, Q. Preparation of a Series of ACTV-Based Covalent Organic Frameworks and Substituent Effects on Their Properties. CrystEngComm 2016, 18 (6), 1039-1045. https://doi.org/10.1039/C5CE02332G.

(9) Li, Y.; Chen, W.; Hao, W.; Li, Y.; Chen, L. Covalent Organic Frameworks Constructed from Flexible Building Blocks with High Adsorption Capacity for Pollutants. ACS Appl. Nano Mater. 2018, 1 (9), 4756-4761. https://doi.org/10.1021/acsanm.8b00983.

(10) Zhang, M.; Chen, J.; Zhang, S.; Zhou, X.; He, L.; Sheridan, M. V; Yuan, M.; Zhang, M.; Chen, L.; Dai, X.; Ma, F.; Wang, J.; Hu, J.; Wu, G.; Kong, X.; Zhou, R.; Albrecht-Schmitt, T. E.; Chai, Z.; Wang, S. Electron Beam Irradiation as a General Approach for the Rapid Synthesis of Covalent Organic Frameworks under Ambient Conditions. J. Am. Chem. Soc. 2020, 142 (20), 9169-9174. https://doi.org/10.1021/jacs.0c03941.

(11) Mullangi, D.; Nandi, S.; Shalini, S.; Sreedhala, S.; Vinod, C. P.; Vaidhyanathan, R. Pd Loaded Amphiphilic COF as Catalyst for Multi-Fold Heck Reactions, C-C Couplings and CO Oxidation. Sci. Rep. 2015, 5 (1), 10876. https://doi.org/10.1038/srep10876.

(12) Zhang, M.; Zheng, R.; Ma, Y.; Chen, R.; Sun, X.; Sun, X. N-Rich Covalent Organic Frameworks with Different Pore Size for High-Pressure CO2 Adsorption. Microporous Mesoporous Mater. 2019, 285, 70-79. https://doi.org/https://doi.org/10.1016/j.micromeso.2019.04.021.

(13) Lin, S.; Hou, Y.; Deng, X.; Wang, H.; Sun, S.; Zhang, X. A Triazine-Based Covalent Organic Framework/Palladium Hybrid for One-Pot Silicon-Based Cross-Coupling of Silanes and Aryl lodides. RSC Adv. 2015, 5 (51), 41017-41024. https://doi.org/10.1039/C5RA04433B.

(14) Xu, L.; Ding, S.-Y.; Liu, J.; Sun, J.; Wang, W.; Zheng, Q.-Y. Highly Crystalline Covalent Organic Frameworks from Flexible Building Blocks. Chem. Commun. 2016, 52 (25), 4706-4709. https://doi.org/10.1039/C6CC01171C.

(15) Liu, X.-H.; Mo, Y.-P.; Yue, J.-Y.; Zheng, Q.-N.; Yan, H.-J.; Wang, D.; Wan, L.-J. Isomeric Routes to Schiff-Base Single-Layered Covalent Organic Frameworks. Small 2014, 10 (23), 4934-4939. https://doi.org/https://doi.org/10.1002/smll.201400899.

(16) Zhu, D.; Verduzco, R. Ultralow Surface Tension Solvents Enable Facile COF Activation with Reduced Pore Collapse. ACS Appl. Mater. Interfaces 2020, 12 (29), 33121-33127. https://doi.org/10.1021/acsami.0c09173.

(17) Mullangi, D.; Shalini, S.; Nandi, S.; Choksi, B.; Vaidhyanathan, R. Super-Hydrophobic Covalent 
Organic Frameworks for Chemical Resistant Coatings and Hydrophobic Paper and Textile Composites. J. Mater. Chem. A 2017, 5 (18), 8376-8384. https://doi.org/10.1039/C7TA01302G.

(18) Mullangi, D.; Dhavale, V.; Shalini, S.; Nandi, S.; Collins, S.; Woo, T.; Kurungot, S.; Vaidhyanathan, R. Low-Overpotential Electrocatalytic Water Splitting with Noble-Metal-Free Nanoparticles Supported in a Sp3 N-Rich Flexible COF. Adv. Energy Mater. 2016, 6 (13), 1600110. https://doi.org/https://doi.org/10.1002/aenm.201600110.

(19) Sek, D.; Grabiec, E.; Janeczek, H.; Jarzabek, B.; Kaczmarczyk, B.; Domanski, M.; Iwan, A. StructureProperties Relationship of Linear and Star-Shaped Imines with Triphenylamine Moieties as HoleTransporting Materials. Opt. Mater. (Amst). 2010, 32 (11), 1514-1525. https://doi.org/https://doi.org/10.1016/j.optmat.2010.06.013.

(20) Grigoras, M.; Stafie, L. Synthesis and Characterization of Linear, Branched and Hyperbranched Triphenylamine-Based Polyazomethines. Des. Monomers Polym. 2009, 12 (2), 177-196. https://doi.org/10.1163/156855509X412117.

(21) Chen, X.; Addicoat, M.; Irle, S.; Nagai, A.; Jiang, D. Control of Crystallinity and Porosity of Covalent Organic Frameworks by Managing Interlayer Interactions Based on Self-Complementary $\pi$ Electronic Force. J. Am. Chem. Soc. 2013, 135 (2), 546-549. https://doi.org/10.1021/ja3100319.

(22) Spitler, E. L.; Koo, B. T.; Novotney, J. L.; Colson, J. W.; Uribe-Romo, F. J.; Gutierrez, G. D.; Clancy, P.; Dichtel, W. R. A 2D Covalent Organic Framework with 4.7-Nm Pores and Insight into Its Interlayer Stacking. J. Am. Chem. Soc. 2011, 133 (48), 19416-19421. https://doi.org/10.1021/ja206242v.

(23) Walton, K. S.; Snurr, R. Q. Applicability of the BET Method for Determining Surface Areas of Microporous Metal-Organic Frameworks. J. Am. Chem. Soc. 2007, 129 (27), 8552-8556. https://doi.org/10.1021/ja071174k.

(24) Rouquerol, J.; Llewellyn, P.; Rouquerol, F. Is the BET Equation Applicable to Microporous Adsorbents?; 2021; pp 49-56. https://doi.org/10.1016/s0167-2991(07)80008-5.

(25) Baker, J. L.; Jimison, L. H.; Mannsfeld, S.; Volkman, S.; Yin, S.; Subramanian, V.; Salleo, A.; Alivisatos, A. P.; Toney, M. F. Quantification of Thin Film Crystallographic Orientation Using X-Ray Diffraction with an Area Detector. Langmuir 2010, 26 (11), 9146-9151. https://doi.org/10.1021/la904840q.

(26) Colson, J. W.; Woll, A. R.; Mukherjee, A.; Levendorf, M. P.; Spitler, E. L.; Shields, V. B.; Spencer, M. G.; Park, J.; Dichtel, W. R. Oriented 2D Covalent Organic Framework Thin Films on Single-Layer Graphene. Science (80-. ). 2011, 332 (6026), 228 LP - 231.

https://doi.org/10.1126/science.1202747. 